\title{
Sofisticação política e opinião pública no Brasil: revisitando hipóteses clássicas
}

\begin{tabular}{c}
\hline \hline Frederico Batista Pereira \\
Doutorando em Ciência Política \\
Vanderbilt University \\
\hline \hline
\end{tabular}

\begin{abstract}
Resumo: $\mathrm{O}$ artigo analisa o impacto da desigualdade de sofisticação política sobre as preferências políticas dos cidadãos. Após uma discussão sobre o conceito e a mensuração da sofisticação política, examina-se seus principais determinantes utilizando dados de uma pesquisa de painel realizada em Caxias do Sul e Juiz de Fora ao longo de 2002. Em seguida, o artigo examina quatro hipóteses da literatura acerca do efeito da sofisticação política sobre a maneira como os eleitores processam informações e opinam: 1) eleitores mais sofisticados apresentam maior estruturação ideológica em suas opiniões do que eleitores menos sofisticados; 2) eleitores mais sofisticados possuem opiniões políticas mais estáveis ao longo do tempo do que os politicamente menos sofisticados; 3) eleitores mais sofisticados adquirem mais informações políticas ao longo do tempo do que eleitores menos sofisticados, e; 4) eleitores mais sofisticados emitem opiniões com maior frequência do que eleitores menos sofisticados. As análises no artigo dão amplo suporte a essas hipóteses. Por fim, discute-se as implicações dos achados para os estudos de opinião pública e voto no Brasil.
\end{abstract}

Palavras-chave: sofisticação política; comportamento político; atitudes

Abstract: This article analyzes the impact of political sophistication on citizens' political preferences. After defining the concept and measurement of political sophistication, panel survey data from Caxias do Sul and Juiz de Fora in 2002 are used to assess its main determinants in the Brazilian context. Next, the article tests four hypotheses derived from existing scholarship about the effects of political sophistication on individual preferences and information processing. The four hypotheses tested are: 1) more politically sophisticated citizens are more ideologically constrained in their political attitudes then less sophisticated individuals; 2) more sophisticated citizens present more stable attitudes over time than less sophisticated individuals; 3) more sophisticated citizens acquire more political information over time than less sophisticated individuals, and; 4) more sophisticated citizens tend to express opinions more frequently than less sophisticated individuals. The analyses in the paper provide strong support for all four hypotheses. Finally, the article discusses some implications of the results for the study of public opinion and elections in Brazil.

Keywords: political sophistication; political behavior; attitudes 


\section{Introdução ${ }^{1}$}

Em que medida os cidadãos de uma democracia apresentam diferentes níveis de apreensão da política? Há desigualdade no que se refere às suas capacidades para acompanhar e compreender o que acontece? E por que isso importa? Este artigo pretende discutir e examinar empiricamente essas perguntas. Embora boa parte da produção na Ciência Política brasileira dedique-se ao estudo da racionalidade do comportamento dos cidadãos, nem tanta atenção tem sido dada ao problema da desigualdade de interesse e conhecimento sobre política. A maior parte dos trabalhos que se dedicam mais sistematicamente ao efeito de tais fatores sobre o público já foi produzida há algum tempo (LAMOUNIER, 1978; 1980; ReIS, 1978; ReIS \& CAStRo, 1992; CASTRO, 1994)2.

O presente artigo propõe que o conceito de sofisticação política é central no debate sobre comportamento eleitoral e opinião pública. O conceito refere-se, em termos gerais, ao entendimento que o cidadão tem a respeito dos objetos e dos fatos do mundo da política. Partindo das discussões de um conjunto relevante de autores, o artigo mostra de que maneira a sofisticação política dos eleitores serve para estratificar o público quanto às diferentes maneiras por meio das quais os cidadãos opinam e escolhem. Quatro hipóteses sobre o tema são empiricamente testadas nas análises que seguem. Em primeiro lugar, a sofisticação política aumenta a estruturação ideológica das opiniões dos cidadãos, no sentido de que opiniões sobre diferentes assuntos tendem a se basear em um mesmo eixo ideológico. Segundo, a sofisticação faz com que as opiniões sejam mais estáveis ao longo do tempo, o que resulta do fato de que as opiniões dos mais sofisticados são baseadas em considerações mais sólidas e consistentes. Terceiro, e diretamente conectada à hipótese anterior, a sofisticação política facilita o aprendizado de novas informações, sendo os cidadãos mais sofisticados também os que mais adquirem informações novas ao longo do tempo, especialmente nas campanhas. Por fim, os mais sofisticados são também os que com maior frequência expressam opiniões quando perguntados, uma vez que tendem a possuir opiniões formadas. Obviamente, as duas últimas hipóteses não implicam que os cidadãos mais sofisticados nunca mudem de opinião, mas sim que é preciso informações novas e mais salientes para que isso ocorra. O artigo não apenas testa empiricamente as quatro hipóteses, como também discute a teorização a respeito dos mecanismos causais que as justificam.

Se as hipóteses propostas estão corretas, elas sugerem implicações importantes para o estudo da dinâmica da opinião pública no Brasil. Interpretações que exacerbam a complexidade dos componentes ideológicos da opinião pública podem contrariar evidências a respeito da racionalidade de parte significativa dos eleitores. Também é relevante levar-se em conta, especialmente no estudo dos efeitos de campanha, quais são os eleitores mais propensos a mudarem de opinião e por qual razão isso ocorre.

Sendo assim, o artigo divide-se em quatro partes principais. Na próxima seção, o conceito de sofisticação política é discutido em suas diferentes dimensões e diferenciado de outras noções com as quais é geralmente confundido. Em seguida, discutem-se as principais estratégias de mensuração do

\footnotetext{
${ }^{1}$ Este artigo foi desenvolvido como parte de minha Dissertação de Mestrado defendida no Departamento de Ciência Política da Universidade Federal de Minas Gerais (UFMG) em 2010. Agradeço a Lucio Rennó por ceder os dados utilizados nas análises. Sou enormemente grato aos comentários de Fábio Wanderley Reis, Mônica Mata Machado de Castro e Mario Fuks em versões anteriores do artigo. Os erros que persistem são de minha inteira responsabilidade.

${ }^{1}$ Algumas exceções recentes são os trabalhos de Rennó (2004; 2006) e Turgeon \& Rennó (2010).
} 
BATISTA PEREIRA, F. Sofisticação política e opinião pública no Brasil: revisitando...

conceito, e também é apresentada a medida de sofisticação política usada nas análises do artigo. A terceira seção dedica-se a mostrar que a sofisticação política não é simplesmente uma capacidade inata, mas antes uma habilidade que os cidadãos desenvolvem em diferentes graus por conta de sua socialização em ambientes distintos. Por fim, a quarta seção utiliza diferentes estratégias de análise para testar as quatro hipóteses apresentadas.

As análises do artigo utilizam dados de pesquisa de opinião, algo comum na literatura sobre voto e opinião pública no Brasil. O que há de distinto em relação à maioria dos trabalhos é o uso de dados coletados em painel, isto é, de entrevistas realizadas ao longo do tempo com os mesmos indivíduos. A pesquisa da qual se fala é intitulada "The Dynamics of Political Attitude Formation in a Milieu of Multiple Weak Parties: A Context-Sensitive Analysis of Voting Behavior in Two Brazilian Cities" (BAKER et al, 2006) $^{3}$, e realizou ondas de entrevistas em abril/maio, agosto/setembro e outubro de 2002, maio de 2004, julho e outubro de 2006 nas cidades brasileiras de Juiz de Fora (MG) e Caxias do Sul (RS). Para gerar uma amostra de 2500 entrevistados em cada cidade na onda de abril/maio de 2002, o procedimento de múltiplos estágios foi utilizado com amostragem aleatória no nível da vizinhança, seguido do setor censitário, depois domicílio e, por fim, pessoas. Ao final da primeira onda, $74 \%$ do total das pessoas contatadas foram entrevistadas, e a mesma porcentagem foi obtida em 2002. Desses, 84\% foram entrevistados na terceira onda de outubro de 2002. Neste artigo, são utilizados apenas os dados referentes às ondas de $2002^{4}$. Ainda que os dados não representem a totalidade do eleitorado brasileiro, acredita-se que os resultados apresentados a seguir não sejam específicos das duas cidades em questão, tampouco do período de tempo coberto pelos dados, mas sim, que corroboram hipóteses e mecanismos causais mais gerais que já foram testados em diferentes contextos.

\section{O conceito de sofisticação política}

O primeiro grupo de estudiosos a abordar mais sistematicamente a ideia de que os cidadãos apresentam diferentes níveis de compreensão dos assuntos políticos foi a chamada Escola de Michigan (CAMPBell et al, 1960; ConVERSE, 1964). A partir da contribuição desses autores, diversos conceitos e termos foram cunhados com referência à existência do domínio e uso das informações e ideias relacionadas ao universo da política. Sofisticação (NEUMAN, 1986; LUSKIN, 1987; 1990; SNIDERMAN et al, 1991; CAstro, 1994) e conhecimento (Delli CARPINI \& KeEter, 1996; NIEMI \& JUNN, 1998) são os dois principais.

Segundo Converse (1964), o entendimento de um cidadão a respeito da política divide-se em alguns subtipos. O primeiro refere-se à posse de um sistema de crenças estruturado, ou seja, da configuração de ideias e atitudes políticas funcionalmente interdependentes (CONVERSE, 1964, p. 207). Nesse primeiro subtipo, não apenas a compreensão, mas também a adesão a algum sistema de crenças ideológico típico de cada sistema político seria importante. O segundo subtipo de entendimento da política seria, segundo Converse, a própria posse de informações políticas. Mais especificamente, a posse de informações políticas seria uma das fontes principais de estruturação dos sistemas de crenças ideológicos (CONVERSE, 1964, p. 212). Converse descreve ainda outro tipo de

3 O artigo em questão contém informações detalhadas a respeito da pesquisa. Os trabalhos de Rennó (2004; 2006; 2007) mencionados ao longo do artigo também utilizam os mesmos dados.

${ }^{4}$ Nos procedimentos de análise estatística, foi utilizado o programa $R$ (<http://www.r.project.org/>). 
conhecimento político, o mais importante, aquele responsável por conectar as informações e atitudes políticas do indivíduo, que seria o "conhecimento contextual" da política (CONVERSE, 1964, p. 212). A medida de "conhecimento contextual" utilizada pelo autor consiste em um escore de "reconhecimento e entendimento" dos termos mais comuns dos sistemas de crenças conservador e liberal nos Estados Unidos, medida baseada nas respostas dadas pelos respondentes a questões abertas sobre suas opiniões em diversos assuntos políticos.

De todo modo, a ênfase maior de Converse ao tratar do entendimento que os cidadãos teriam da política foi na estruturação dos sistemas de crenças políticas (CONVERSE, 1964, p. 227.228). O autor demandava que o cidadão não apenas demonstrasse capacidade de conceituação política, mas também que apresentasse uma adesão consistente a um ou outro sistema de crenças (liberal ou conservador) da política estadunidense, adesão esta que se revelaria a partir de suas opiniões. Kuklinski e Quirk (2002, p. 291) chamam atenção para o fato de que o próprio Converse, em seus trabalhos mais tardios, teria aceitado a possibilidade de que um cidadão poderia ser politicamente sofisticado sem, necessariamente, aderir a um ou outro pólo ideológico ao tomar posição nos assuntos da política. Nesse sentido, capacidade de conceituação e adesão à ideologia seriam atributos conceitualmente distintos, sendo que o entendimento que o cidadão possui da política seria mais diretamente aferido através da mensuração da primeira, e não da segunda.

A distinção conceitual entre sofisticação política e ideologia tornou-se mais clara nos estudos posteriores que se apoiaram no legado teórico de Converse. Neuman (1981), por exemplo, tratou de rechaçar a confusão existente. Segundo ele,

"It seems to make strategic sense at the current stage of inquiry to maintain a clear distinction between the definitional components of ideology and sophistication and to pursue unique measures of each. One individual may study history and politics and after a thoughtful review of issues and events come to an "ideological" position. In contrast, another may simply be repeating slogans and abstractions absorbed uncritically from friends and associates" (NEUMAN, 1981, p. 1239).

A principal noção que pretende abarcar a existência desse atributo desigualmente distribuído entre os cidadãos é a chamada sofisticação política. Vale a pena reproduzir aqui a definição dada por Luskin (1990):

\footnotetext{
"More precisely, a person is politically sophisticated to the extent to which his or her political cognitions are numerous, cut a wide substantive swath, and are highly organized, or "constrained". Some psychologists write in this vein of cognitive complexity, meaning the extent to which a person's cognitions of some stimulus domain are both highly differentiated (roughly, numerous and wide-ranging) and highly integrated (organized or constrained)" (LUSKIN, 1990, p. 332).
}

A literatura também tem concordado que a sofisticação pode desdobrar-se em, pelo menos, duas dimensões conceituais distintas. Neuman referiu-se à capacidade de identificar e discriminar os diversos assuntos, pessoas e fatos da política como sendo a dimensão da diferenciação conceitual (NEUmAN, 1981, p. 1237). Já a organização das ideias e assuntos políticos em construtos mais abstratos seria a segunda dimensão da sofisticação política, a integração conceitual (NEUMAN, 1981, p. 1237). Luskin lançou mão de termos diferentes para referir-se às mesmas dimensões. Inicialmente, 
BATISTA PEREIRA, F. Sofisticação política e opinião pública no Brasil: revisitando...

o autor identificou três dimensões principais (LUSKIN, 1987, p. 859): o número de informações, a amplitude de assuntos que tais informações cobrem no universo da política e a organização ou a interconexão entre as informações ou cognições políticas do cidadão. No entanto, Luskin também sugeriu a possibilidade de se entender as duas primeiras dimensões (quantidade e amplitude) como traduzidas na noção de diferenciação conceitual proposta por Neuman, e concedeu ainda que o que chamou de organização seria equivalente à noção de integração conceitual (LUSKIN, 1987, p. 861).

\section{A medida de sofisticação política}

A sofisticação política tem sido medida por diversas estratégias nas principais pesquisas acadêmicas de opinião pública. Luskin (1987) cobre parte das controvérsias a respeito. Segundo o autor, as medidas de diferenciação conceitual consistiriam em perguntas mais diretas (fechadas ou abertas) sobre a posse de informações factuais sobre política. Para Luskin, esse procedimento simples produziria medidas bastante consistentes. Já no que se refere às medidas de integração conceitual, Luskin não demonstrou tanto otimismo. Tais medidas geralmente baseariam-se na avaliação da capacidade dos respondentes de associar corretamente pessoas e partidos aos "lados" da política estadunidense, ou na construção de escores a partir da codificação das respostas dadas a questões abertas nas quais o respondente demonstraria a capacidade de reconhecer e entender conceitos mais abstratos da política (LUSKIN, 1987, p. 881-882). Neuman (1981) mediu a dimensão da integração conceitual utilizando análise de conteúdo de entrevistas em profundidade. $O$ autor não apenas enumerou as referências a conceitos abstratos feitas pelos respondentes, como também pediu que os codificadores das entrevistas avaliassem as respostas com relação a padrões mais gerais de organização, conexão e contraste entre as ideias de cada entrevistado. Avaliações feitas por codificadores diferentes apresentaram, em geral, alta correlação entre si, o que indicaria a consistência das medidas (NEUMAN, 1981, p. 1248). Luskin também propôs uma medida que distinguiria as respostas dadas às questões abertas sobre a ideologia dos partidos quanto aos seus níveis de acerto e abstração (LUSKIN, 1987, p. 882).

Apesar de reconhecer que as medidas típicas de integração conceitual teriam alguma validade, Luskin questionou sua capacidade de discriminar adequadamente os respondentes. De acordo com ele, tais indivíduos poderiam associar palavras a conceitos que não necessariamente desempenhariam qualquer função em organizar suas ideias sobre política, ou poderiam simplesmente lembrar-se de certas considerações de forma um tanto acidental e obter escores maiores do que os reais (LUSKIN, 1987, p. 882). Além disso, outra desvantagem das questões abertas para medir integração conceitual seria que o espaço que tais baterias de perguntas ocuparia em pesquisas de opinião limitaria o espaço disponível para outras questões também importantes (LUSKIN, 1987, p. 892).

Com base nessa desconfiança em relação às medidas da dimensão da sofisticação chamada de integração conceitual, Luskin defendeu que as medidas convencionais de posse de informações factuais sobre política poderiam ser utilizadas como aproximações do construto mais geral da sofisticação, uma vez que seriam altamente correlacionadas às medidas supostamente menos confiáveis de integração (LUSKIN, 1987, p. 890). Outros estudos de grande relevância sobre o tema também basearam-se exclusivamente nas medidas simples de informação. Delli Carpini e Keeter (1996, p.10) optaram por falar em conhecimento político como um conceito mais restrito, referido apenas ao 
conjunto de informações políticas factuais armazenadas na memória de longo prazo dos indivíduos. Para esses autores, essa noção permitiria construir indicadores mais objetivos de conhecimento, contando com a precisão e a confiabilidade de medidas com apenas respostas certas ou erradas. Essa postura é encontrada também em outro trabalho de referência na área (NIEMI \& JUNN, 1998, p. 11.12).

No Brasil, Reis e Castro (1992) utilizaram medidas de posse de informações em seu estudo, além de questões sobre envolvimento com política e capacidade de conceituação. Em sua tese, Castro (1994) apoiou-se em Neuman (1986) e também usou perguntas sobre interesse por política e exposição à informação. Rennó $(2004,2006,2007)$ incluiu em sua medida de informação não apenas as questões de posse de informações factuais, mas também uma medida de "opinação", que indica a quantidade de opiniões emitidas pelos respondentes. Em trabalho mais recente, Fuks e Batista Pereira (2011) também utilizaram dados de survey para construir medidas consistentes e válidas de posse de informações factuais e conceituação política.

A medida de sofisticação política utilizada nas análises a seguir baseia-se em uma bateria de perguntas de informações factuais que foi aplicada na onda de abril da pesquisa em Juiz de Fora e Caxias do Sul. Optou-se aqui por seguir Luskin (1987) quando este afirma que a medida de posse de informações factuais seria representativa do construto mais geral da sofisticação. Ao final da aplicação do questionário de abril, foram incluídas seis questões de múltipla escolha que buscavam medir a posse de informações políticas. Os respondentes foram perguntados sobre quem era o vice.Presidente do Brasil na época; o partido do então Presidente Fernando Henrique Cardoso; qual país em uma lista fazia parte do MERCOSUL; e também o nome do então presidente da Câmara dos Deputados. Outras duas perguntas eram específicas de cada cidade, porém análogas entre si. Uma pedia que o respondente identificasse, entre quatro alternativas, aquela que continha o nome de um senador de seu estado. Outra pergunta mencionava o nome de um político (um deputado federal da cidade) e pedia que o respondente identificasse seu cargo. As demais alternativas nas duas perguntas eram iguais para Caxias do Sul e Juiz de Fora. A Tabela 1 apresenta a proporção dos acertos nessas questões, bem como os fraseados utilizados e as alternativas de resposta fornecidas:

Tabela 1

Percentual de acertos nas questões de informação política

\begin{tabular}{|c|c|c|c|}
\hline $\begin{array}{c}\text { Perguntas } \\
\text { (Opções de respostas: resposta correta sublinhada) }\end{array}$ & $\begin{array}{l}\text { Caxias do Sul } \\
(n=2434)\end{array}$ & $\begin{array}{l}\text { Juiz de Fora } \\
(n=2448)\end{array}$ & $\begin{array}{l}\text { Amostra Total } \\
(n=4882)\end{array}$ \\
\hline $\begin{array}{l}\text { Qual é o cargo da Ana Corso/Paulo Delgado? } \\
\text { (Vereador; Deputado Estadual; Deputado Federal;Senador) }\end{array}$ & 51,19 & 47,92 & 49,55 \\
\hline $\begin{array}{l}\text { Quem é o vice-presidente do Brasil? } \\
\text { (Inocêncio de Oliveira; Marco Maciel; Íris Resende; Marcello } \\
\text { Alencar) }\end{array}$ & 57,11 & 59,76 & 58,44 \\
\hline $\begin{array}{l}\text { A qual partido pertence Fernando Henrique Cardoso? } \\
\text { (PTB; PMDB; PSDB; PFL) }\end{array}$ & 38,37 & 48,73 & 43,57 \\
\hline $\begin{array}{l}\text { Qual dos seguintes países é membro do MERCOSUL? } \\
\text { (Estados Unidos; Argentina; Colômbia; Peru) }\end{array}$ & 73,25 & 61,36 & 67,29 \\
\hline $\begin{array}{l}\text { Qual destes é um senador do estado do Rio Grande do } \\
\text { Sul/Minas Gerais? } \\
\text { (José Fogaça/José Alencar; Saturnino Braga; Eduardo Suplicy; } \\
\text { Lindbergh Cury) }\end{array}$ & 65,20 & 57,31 & 61,25 \\
\hline $\begin{array}{l}\text { Quem é o presidente da Câmara dos Deputados? } \\
\text { (Roberto Jefferson; José Genuíno; Aécio Neves; Miro Teixeira) }\end{array}$ & 28,84 & 53,06 & 40,99 \\
\hline
\end{tabular}

Fonte: Elaboração do autor a partir dos dados de Baker et al (2006). 
BATISTA PEREIRA, F. Sofisticação política e opinião pública no Brasil: revisitando...

A constatação a partir da análise da Tabela 1 depende das expectativas prévias que se tem sobre qual é a proporção de acertos desejada. Contudo, ao analisar o conteúdo das perguntas, não é difícil concluir que nenhuma se refere a questões complicadas ou remotas sobre o sistema político brasileiro. Pelo contrário, algumas perguntas podem ser consideradas extremamente fáceis. No entanto, em nenhuma das cidades, a proporção de acertos na questão que perguntava o partido do então Presidente da República chega a 50\%. Mais de 40\% dos respondentes não souberam o nome do vice-Presidente do Brasil. No agregado, apenas $40 \%$ dos respondentes souberam identificar o nome do presidente da Câmara dos Deputados. A questão com maior proporção de acertos foi a que pedia que o respondente identificasse o país do MERCOSUL em um conjunto de quatro alternativas, mas mesmo assim não passou de $70 \%$ a proporção de respostas corretas nas duas cidades. 0 que se pode concluir é que há variação relevante nos níveis de sofisticação política dos respondentes, sendo que parte substantiva das pessoas respondeu incorretamente a perguntas relativamente fáceis sobre a política no Brasil.

A medida final de sofisticação política utilizada nas análises deste artigo foi construída a partir da teoria de resposta ao item - TRI (BIRNBAUM, 1968; BAKER, 2001; OSTERLIND, 1983) ${ }^{5}$. Em linhas gerais, essa forma de conceber o teste entende que o desempenho de um indivíduo em uma questão depende da dificuldade do teste e da habilidade latente do indivíduo. Diferentemente do uso do simples somatório do número de acertos, a construção do índice por essa técnica permite levar em conta os diferentes pesos das respostas em cada questão sobre o construto final, uma vez que os itens diferenciam-se por sua dificuldade e por sua capacidade de discriminar os respondentes no atributo. 0 resultado é que a escala construída possui bem mais do que 7 pontos, número de pontos obtido caso fosse usado o simples somatório. Com as questões tendo pesos diferentes no construto, obtêm-se mais pontos na escala e, por conseguinte, maior variabilidade entre os indivíduos no atributo mensurado. Por outro lado, a construção desse tipo de fator, em geral, produz escores padronizados de difícil interpretação. Para tentar resolver esse problema, o construto obtido por TRI foi re-escalado de modo que o valor mínimo passasse a ser igual a 0 e o máximo igual a 6 . Isso fez com que a escala tivesse uma interpretação mais próxima da escala aditiva do número de acertos.

\section{Os determinantes da sofisticação política}

Este tópico pretende examinar alguns correlatos da aquisição de sofisticação política e discutir brevemente os processos por meio dos quais os indivíduos desenvolvem tal atributo. Trata-se de uma discussão que não é de forma alguma nova na Ciência Política em geral, e tampouco na Ciência Política brasileira. Alguns autores brasileiros já procuraram mostrar que as desigualdades de envolvimento e sofisticação política traduzem em desigualdades estruturais da sociedade no âmbito do comportamento político. Reis referiu-se a esse fenômeno em diversos textos a partir da articulação entre os modelos da "centralidade" e da "consciência de classe" para explicar a participação política (REIS, 1978; 2000; REIS \& CASTRO, 1992). O chamado "modelo da centralidade" postularia que a participação política dar-se-ia com mais intensidade entre os indivíduos mais próximos do centro do sistema político, tanto do ponto de vista de uma dimensão horizontal, referida à localização geográfica, quanto de uma dimensão vertical, referida à desigualdade de características sociodemográficas e

${ }^{5}$ A discussão mais detalhada do procedimento é apresentada no Apêndice. 
econômicas. O "modelo da consciência de classe", por sua vez, proporia que a participação seria mais intensa entre os indivíduos portadores da consciência de classe, isto é, do conhecimento a respeito das conexões entre os próprios interesses e os eventos políticos. A articulação entre esses dois modelos, segundo Reis (2000, p. 76-77), redundaria precisamente em que seriam os indivíduos oriundos de posições mais centrais, tanto objetiva quanto subjetivamente em relação ao sistema político, os mais propensos a manifestarem a chamada "consciência de classe". Nesse sentido, a participação intensa e sofisticada conectar-se-ia de forma sistemática com atributos relacionados ao status socioeconômico e à experiência urbana dos indivíduos. Os trabalhos de Reis e de outros autores que se baseiam nessas mesmas considerações, como Lamounier (1975; 1978; 1980) e Castro (1994), mostraram que atributos como renda, ocupação, idade e escolaridade estariam associados à sofisticação política dos indivíduos. Rennó (2007), utilizando os mesmos dados do presente artigo, mostrou que as informações políticas seriam distribuídas de forma desigual em Juiz de Fora e Caxias do Sul, e que isso estaria associado tanto à desigualdade em atributos socioeconômicos dos cidadãos, como renda, escolaridade, sexo e raça, quanto a fatores ambientais, isto é, à própria existência de ambientes onde seria mais fácil informar-se sobre política. Outro artigo que discute a aquisição da sofisticação é o de Fuks e Batista Pereira (2011), no qual os autores analisam jovens secundaristas de Belo Horizonte e sugerem haver diferentes dinâmicas de aquisição para as duas dimensões conceituais da sofisticação política.

Os dados da pesquisa de Caxias do Sul e Juiz de Fora permitem verificar em que medida a sofisticação política traduz sistematicamente desigualdades socioeconômicas. A Tabela 2 apresenta os resultados de modelos de regressão linear ajustados para toda a amostra e para cada cidade analisada tendo como variável dependente o escore de sofisticação política apresentado anteriormente ${ }^{6}$.

\footnotetext{
${ }^{6} \mathrm{~A}$ apresentação dos resultados para cada cidade serve apenas para mostrar que não há grandes diferenças entre as duas no que se refere a essa análise.
} 
BATISTA PEREIRA, F. Sofisticação política e opinião pública no Brasil: revisitando...

Tabela 2

Regressões lineares tendo como variável dependente o nível de sofisticação política por cidade e total

\begin{tabular}{|c|c|c|c|}
\hline \multirow[b]{2}{*}{ Variáveis independentes } & Juiz de Fora & Caxias do Sul & Amostra total \\
\hline & $\begin{array}{c}\text { Coeficiente não padronizado } \\
\text { (Erro Padrão) }\end{array}$ & $\begin{array}{c}\text { Coeficiente não padronizado } \\
\text { (Erro Padrão) }\end{array}$ & $\begin{array}{c}\text { Coeficiente não } \\
\text { padronizado } \\
\text { (Erro Padrão) }\end{array}$ \\
\hline \multirow{2}{*}{ Intercepto } & $\cdot 1,66^{* * *}$ & $-0,89 * * *$ & $-1,26^{* * *}$ \\
\hline & $(0,22)$ & $(0,21)$ & $(0,16)$ \\
\hline \multirow{2}{*}{ Renda Familiar } & $0,000^{* *}$ & $0,00 * * *$ & $0,00^{* * * *}$ \\
\hline & $(0,000)$ & $(0,00)$ & $(0,00)$ \\
\hline \multirow{2}{*}{ Anos de escolaridade } & $0,22^{* * * *}$ & $0,15^{* * * *}$ & $0,19^{* * * *}$ \\
\hline & $(0,01)$ & $(0,01)$ & $(0,01)$ \\
\hline \multirow{2}{*}{ Sexo (Mulher $=0$ ) } & $1,06 * * *$ & $0,65^{* * *}$ & $0,87 * * *$ \\
\hline & $(0,07)$ & $(0,07)$ & $(0,05)$ \\
\hline \multirow{2}{*}{ Branco (Outros $=0$ ) } & $0,46^{* * *}$ & 0,18 & $0,31^{* * *}$ \\
\hline & $(0,15)$ & $(0,14)$ & $(0,10)$ \\
\hline \multirow{2}{*}{ Pardo (Outros $=0$ ) } & 0,13 & 0,09 & 0,09 \\
\hline & $(0,16)$ & $(0,16)$ & $(0,11)$ \\
\hline \multirow{2}{*}{ Preto (Outros $=0$ ) } & 0,00 & $.0,12$ & $.0,11$ \\
\hline & $(0,17)$ & $(0,22)$ & $(0,13)$ \\
\hline \multirow{2}{*}{ Idade } & $0,03^{* * *}$ & $0,02^{* * *}$ & $0,03^{* * *}$ \\
\hline & $(0,00)$ & $(0,00)$ & $(0,01)$ \\
\hline \multirow{2}{*}{ Exposição à TV } & $0,05^{* * *}$ & $0,08 * * *$ & $0,06 * * *$ \\
\hline & $(0,01)$ & $(0,01)$ & $(0,01)$ \\
\hline \multirow{2}{*}{ Exposição a outros meios } & $0,06 * * *$ & $0,06 * * *$ & $0,06 * * *$ \\
\hline & $(0,01)$ & $(0,01)$ & $(0,01)$ \\
\hline \multirow{2}{*}{ Exposição em conversas } & $0,37 * * *$ & $0,48 * * *$ & $0,42^{* * *}$ \\
\hline & $(0,06)$ & $(0,07)$ & $(0,05)$ \\
\hline \multirow{2}{*}{ Associativismo } & $.0,01$ & $.0,01$ & 0,00 \\
\hline & $(0,08)$ & $(0,07)$ & $(0,05)$ \\
\hline \multirow{2}{*}{ Cidade (Juiz de Fora $=0$ ) } & & & $.0,06$ \\
\hline & $\cdot$ & $\cdot$ & $(0,05)$ \\
\hline $\mathrm{n}$ & 2105 & 2026 & 4131 \\
\hline $\mathrm{R}^{2}$ Ajustado & 0,41 & 0,36 & 0,39 \\
\hline Teste F & $136,3^{* * *}$ & $103,2^{* * * *}$ & $216,4^{* * *}$ \\
\hline
\end{tabular}

*** Estatisticamente significativo a 0,01

Fonte: Elaboração do autor a partir dos dados de Baker et al (2006).

Entre as variáveis independentes do modelo estão renda (medida em Reais) ${ }^{7}$, escolaridade (medida em anos completos de escolaridade) ${ }^{8}$, sexo (binário, tendo a categoria "mulher" como referência), raça (composta por três variáveis indicadoras, e tendo a categoria "outras" como referência), e idade (medida em anos completos). Quatro construtos contínuos também foram inseridos $^{9}$. As variáveis de "exposição à TV" e "exposição a outros meios" têm como unidade a quantidade de vezes por semana que o respondente alega ter contato com cada meio de comunicação. As variáveis de "exposição em conversas" e "associativismo" também foram medidas por baterias de perguntas com escalas do tipo Likert sobre a frequência de realização da atividade (nunca, raramente, algumas vezes ou sempre). Esses construtos também foram feitos a partir de modelos de teoria de reposta ao item e, assim como o construto de informação, foram re-escalados de modo a variarem entre 0 (nunca) e 3 (sempre). No modelo de regressão ajustado para toda a amostra, foi inserida uma variável binária de controle que diferencia o pertencimento a cada uma das cidades.

${ }^{7}$ A variável renda continha 669 casos sem informação que foram excluídos da análise.

${ }^{8}$ A variável escolaridade continha 50 casos sem informação que foram excluídos da análise.

${ }^{9} \mathrm{O}$ Apêndice inclui informações mais detalhadas sobre a construção de tais variáveis. 
Para melhorar a leitura dos resultados, a Tabela 3 apresenta o que se chama de simulação dos valores de interesse do modelo ajustado para toda a amostra. Esse procedimento permite visualizar com maior clareza a magnitude dos efeitos de cada variável, além de propiciar a simulação do escore que teriam indivíduos com perfis determinados pelo analista (KING, TOMZ \& WITTEMBERG, 2000; IMAI, KING \& LAU, 2008; 2009) ${ }^{10}$.

Tabela 3

Simulação de valores de interesse a partir da regressão linear da Tabela 2 para toda a amostra

\begin{tabular}{|c|c|c|c|}
\hline Variável & Nível de sofisticação & Variável & Nível de sofisticação \\
\hline \multicolumn{2}{|l|}{ Renda familiar } & \multicolumn{2}{|l|}{ Exposição à TV } \\
\hline Nenhuma & 3,10 & Nenhuma vez por semana & 2,73 \\
\hline Um salário mínimo $(\mathrm{R} \$ 510,00)$ & 3,15 & Duas vezes por semana & 2,86 \\
\hline Cinco salários mínimos & 3,31 & Cinco vezes por semana & 3,05 \\
\hline Dez salários mínimos & 3,52 & \multicolumn{2}{|c|}{ Exposição a outros meios } \\
\hline \multicolumn{2}{|l|}{ Escolaridade } & Nenhuma vez por semana & 3,02 \\
\hline Analfabeto & 1,67 & Duas vezes por semana & 3,14 \\
\hline Ensino Básico completo (4 anos) & 2,41 & Cinco vezes por semana & 3,31 \\
\hline Ensino Fundamental completo ( 8 anos) & 3,15 & \multicolumn{2}{|c|}{ Exposição em conversas } \\
\hline Ensino Médio completo (11 anos) & 3,70 & Nunca & 2,78 \\
\hline Ensino Superior completo (15 anos) & 4,44 & Raramente & 3,19 \\
\hline \multicolumn{2}{|l|}{ Idade } & Algumas vezes & 3,61 \\
\hline 18 anos & 2,59 & Sempre & 4,03 \\
\hline 30 anos & 2,91 & \multicolumn{2}{|l|}{ Associativismo } \\
\hline 50 anos & 3,43 & Nunca & 3,22 \\
\hline \multicolumn{2}{|l|}{ Raça } & Raramente & 3,22 \\
\hline Negro & 3,22 & Algumas vezes & 3,21 \\
\hline Pardo & 3,29 & Sempre & 3,20 \\
\hline Branco & 3,33 & \multicolumn{2}{|l|}{ Cidade } \\
\hline \multicolumn{2}{|l|}{ Sexo } & Juiz de Fora & 3,25 \\
\hline Mulher & 2,80 & Caxias do Sul & 3,19 \\
\hline Homem & 3,67 & & \\
\hline
\end{tabular}

Fonte: Elaboração do autor a partir dos dados de Baker et al (2006).

Os números apresentados na Tabela 3 correspondem aos valores simulados do escore médio de sofisticação política do indivíduo com a característica definida na linha da tabela, e com todas as

10 Essa técnica simula distribuições para os parâmetros estimados (os coeficientes do modelo) por assumir que tais distribuições são normalmente distribuídas. A partir disso, o programa calcula os valores preditos para cada amostra simulada e utiliza a distribuição desses valores preditos para gerar uma estimativa (média) e seu erro (o desvio-padrão). Outra alternativa seria a utilização de bootstrapping, que consiste em uma abordagem ainda mais geral, porém, muito semelhante, que geraria resultados praticamente idênticos. 
BATISTA PEREIRA, F. Sofisticação política e opinião pública no Brasil: revisitando...

demais variáveis mantidas constantes. A variável renda apresenta um efeito positivo sobre a sofisticação política, controlando-se por todas as demais. O efeito parece não ser tão forte, ainda que tal julgamento seja em boa medida subjetivo. A diferença entre um indivíduo que não possui renda (renda igual a 0) e um indivíduo que ganha 10 salários mínimos não chega a meio ponto na escala que vai de 0 a 6 . Já a escolaridade tem um efeito maior. Um indivíduo com Ensino Superior tem um escore médio de 4,44, ao passo que um indivíduo que tem apenas o Ensino Básico, por exemplo, não chega a marcar 2,5 pontos. O efeito da idade também é razoável, com um respondente de 50 anos marcando mais de um ponto a mais que um de 18 anos. Raça, por sua vez, apresenta um efeito muito fraco, ainda que a tabela de regressão informe que ele seja estatisticamente significativo. Por outro lado, a variável "sexo" tem um efeito forte e favorável aos homens, que marcam em média 0,87 pontos a mais do que as mulheres. Os respondentes de Caxias do Sul tendem a ser menos sofisticados do que os de Juiz de Fora, mas essa diferença é muito pequena (0,06 pontos).

No que tange aos efeitos dos construtos contínuos de exposição à informação ou estímulos políticos, nota-se que as duas variáveis de exposição à política nos meios de comunicação têm efeitos apenas moderados. Um indivíduo que nunca assiste ao noticiário político da TV, por exemplo, tem um escore médio apenas 0,3 pontos menor do que o respondente que o faz 5 vezes por semana. $A$ diferença tem quase a mesma magnitude no caso da exposição à informação política por outros meios de comunicação como jornais e revistas. Por outro lado, a variável de exposição às conversas tem um efeito mais forte, com um indivíduo que declara sempre conversar tendo, em média, mais de 1 ponto no escore de sofisticação do que um indivíduo que declara nunca conversar sobre política. A variável de associativismo não tem um efeito substantivo.

Em suma, o modelo ajustado para examinar alguns dos correlatos da sofisticação política ajuda a mostrar que ela traduz desigualdades socioeconômicas e demográficas de forma sistemática. Os resultados corroboram o quadro interpretativo fornecido por Reis (1978), segundo o qual indivíduos em posições mais centrais na sociedade têm maior propensão a reconhecer e manipular os estímulos de natureza política.

\section{O impacto da sofisticação política}

Sniderman e seus colegas chamaram a concepção de que a sofisticação política estratificaria o público entre tipos de tomadores de decisão de "teoria da interação da sofisticação política" (SNIDERMAN et al, 1991, p. 20). No trecho a seguir, os autores caracterizam tal perspectiva:

"[...] political sophistication is a 'bundle' concept: it packs together related, if distinguishable, properties including a tendency to pay close attention to politics, to have ready at hand banks of information about it, to understand multiple arguments for and against particular issue positions, and to recognize interrelationships among those arguments. Indeed, it is precisely because political sophistication implicates so many facets of information processing that it is likely to play a role of high centrality in reasoning about political choices. Differently put, our expectation is that political sophistication not only affects reasoning about political choices in its own right, but in addition affects how other factors affect reasoning about political choices" (SNIDERMAN et al, 1991, p. 21). 
$\mathrm{Na}$ linguagem estatística, a interação refere-se ao caso em que o sentido e a intensidade da associação entre duas variáveis dependem do valor que assume uma terceira, ou mesmo de uma das duas variáveis em questão (BRAMBOR et al, 2006). No caso da perspectiva da interação da sofisticação, a ideia implica que a associação entre duas ou mais atitudes/preferências, ou entre uma mesma atitude em pontos distintos do tempo, depende do nível de sofisticação política do indivíduo. Nesse sentido, indivíduos mais politicamente sofisticados tendem a ter atitudes mais efetivas, ou que se associam de forma mais consistente com outras, e atitudes mais estáveis, isto é, atitudes que são mais consistentes ao longo do tempo. Esse entendimento quanto ao papel da sofisticação política denota que ela é uma variável condicional ou interativa na explicação do comportamento político. Não há razão para supor que a sofisticação política explique a direção das preferências das pessoas.

Mas, de que maneira a sofisticação política estratifica o público entre diferentes tomadores de decisão? Esta seção do artigo pretende explorar a resposta a essa pergunta. Quando expressam suas opiniões sobre um assunto, indivíduos buscam na memória as informações que possuem a respeito do tema em questão (ZALLER, 1992). Caso a maioria dessas informações seja positiva, o indivíduo emitirá uma opinião positiva em relação ao objeto avaliado. Caso contrário, sua avaliação será negativa. A sofisticação política refere-se exatamente ao volume dessas informações e à capacidade dos indivíduos de conectá-las. Tendo como base esse mecanismo, é possível compreender por que certos indivíduos mudam mais de opinião do que outros, e porque certos indivíduos possuem opiniões mais ideologicamente consistentes. A discussão a seguir aborda tais questões e testa quatro hipóteses relevantes sobre de que maneira a sofisticação política estratifica o eleitorado de forma crucial para o estudo da opinião pública.

Vale a pena começar a discussão pela efetividade das atitudes políticas, entendidas aqui como as orientações afetivas (positivas ou negativas, favoráveis ou desfavoráveis) dos indivíduos com relação a objetos da política (KROSNICK \& RAHN, 1994, p. 279). Atitudes efetivas são aquelas que produzem consequências no comportamento dos indivíduos, ou seja, que se conectam de maneira sistemática a outras atitudes e ações (KROSNICK \& RAHN, 1994). O teste mais famoso da conexão entre atitudes políticas é, sem dúvida, o já mencionado estudo de Converse (1964) sobre a estruturação ideológica, que propôs que as atitudes políticas dos indivíduos seriam mais ou menos organizadas em sistemas de crenças, os quais seriam configurações de ideias e atitudes cujos elementos se conectariam por alguma forma de estruturação ou interdependência funcional (CONVERSE, 1964, p. 207). Por estruturação, Converse compreende a correspondência entre atitudes ou o sucesso com que se pode prever a opinião de um indivíduo em uma questão a partir da opinião já conhecida que ele expressa em outra questão. Trata-se precisamente de dizer que um sistema de crenças é estruturado na medida em que um princípio ou orientação mais geral organiza um subconjunto de atitudes.

A hipótese de Converse era que, para a grande maioria do eleitorado estadunidense, as atitudes políticas não se organizariam de forma sistemática em torno dos eixos liberal e conservador da política do país. Isso revelaria que a grande maioria do eleitorado não teria um entendimento muito complexo da política, tendo em vista a maneira idiossincrática na qual organizariam suas atitudes políticas. Para testar sua hipótese, Converse comparou as matrizes de correlação de itens de opinião em questões políticas entre candidatos ao Congresso e entre a massa dos eleitores (CONVERSE, 1964, 
BATISTA PEREIRA, F. Sofisticação política e opinião pública no Brasil: revisitando...

p. 228). Os resultados mostraram correspondência muito maior entre as diferentes opiniões dos candidatos ao Congresso do que entre a massa dos eleitores. Para Converse, a interpretação dos resultados era inequívoca: o volume de informação política, ou seja, o entendimento da política seria responsável por promover a organização ou a efetividade das atitudes políticas, seu impacto mútuo e sobre outros comportamentos na política.

Os ataques ao estudo de Converse vieram de duas correntes principais. A primeira, cujo principal expoente é o estudo de Nie, Verba e Petrocik (1976), tentou mostrar que os eleitorados das décadas seguintes ao estudo de Converse teriam maiores níveis de estruturação ideológica. Esta crítica, no entanto, teve que recuar diante das evidências de que a suposta estruturação verificada no período analisado seria consequência de alterações no formato e no fraseado das questões utilizadas pelos autores (SULLIVAN; PIERESON \& MARCUS, 1978). Outra linhagem de críticos de Converse segue a postura de Achen (1975) e Judd e Milburn (1980), segundo a qual a existência de baixas correlações entre as atitudes dos cidadãos seria causada por erros de mensuração próprios das técnicas de coleta e análise de dados de survey, e não pela falta de consistência ideológica dos eleitores. Esses autores procuraram desenvolver artifícios estatísticos supostamente capazes de minimizar o efeito dos erros de mensuração e elevar o nível de estruturação ideológica dos indivíduos analisados. No entanto, o problema dos erros de mensuração seria menos metodológico do que ontológico (SNIDERMAN et al, 1991, p. 17). Para Converse, ainda que os erros de mensuração sejam parte inevitável da análise dos dados de survey, eles seriam causados pela falta de consistência ideológica derivada da baixa sofisticação política dos respondentes. Para os tributários da posição de Achen, os erros de mensuração se deveriam, exclusivamente, a problemas do survey.

Autores como Sniderman, Brody e Tetlock (1991) entendem que essa contenda teria se resolvido com o trabalho de Stimson (1975), que analisou as correlações entre as atitudes dos indivíduos para diferentes grupos do que chamou de "habilidade cognitiva". Essa variável foi representada pela escolaridade, e o procedimento do autor foi realizar análises fatoriais entre as questões de opinião separadamente para grupos com níveis distintos de escolaridade. O resultado encontrado foi inequívoco: quanto maior o nível de escolaridade, maior a associação entre as atitudes políticas dos respondentes. Anos mais tarde, Delli Carpini e Keeter (1996, p. 237) utilizaram a variável de informações factuais e, também através de modelos de análise fatorial, repetiram os resultados de Stimson. No Brasil, do mesmo modo, os estudos de Lamounier (1978; 1980) e Reis (1978) mostraram que as associações entre opiniões em questões políticas e outras preferências políticas seriam maiores para níveis mais altos de escolaridade. Castro (1994, p. 171.202) também analisou no quinto capítulo de sua tese, por meio de correlações, a associação entre opiniões políticas diversas para grupos de sofisticação política e concluiu que elas seriam maiores nos grupos com níveis mais altos de sofisticação.

Esse conjunto de achados parece indicar que a resposta de Converse sobre a falta de estruturação ideológica do eleitorado seria mesmo a mais adequada. Se as baixas correlações entre atitudes fossem causadas somente por erros de mensuração, seria de se esperar que elas se mantivessem constantes independentemente do nível de entendimento da política apresentado pelo respondente. Como isso não ocorre, sendo exatamente a sofisticação política o fator que explica a variação da estruturação ideológica, pode-se dizer que os chamados erros de mensuração revelam 
exatamente o que Converse sugeria: o efeito da sofisticação política no sentido de aumentar a estruturação dos sistemas de crenças políticas dos cidadãos.

É possível testar a proposição de Converse neste artigo. Três perguntas feitas em abril indagavam se o respondente era favorável ou não às privatizações, aos gastos sociais do governo e à implementação da reforma agrária. Esses itens eram ordinais, com escalas de 5 pontos. Outros quatro itens da onda de setembro tinham formato de escolha forçada, e pediam ao respondente que escolhesse entre alternativas de políticas públicas opostas. Esses itens eram binários. Os respondentes que apareciam nas duas ondas e que deram respostas em todas essas perguntas foram selecionados, totalizando 2922 casos. Os resultados da análise fatorial são apresentados na Tabela $4^{11}$ :

Tabela 4

Análise fatorial por eixos principais dos itens de opiniões políticas por quartil de sofisticação política em toda a amostra

\begin{tabular}{|l|c|c|c|c|c|}
\hline \multicolumn{1}{|c|}{ Questão } & $\begin{array}{c}\text { Quartil 1 } \\
n=625\end{array}$ & $\begin{array}{c}\text { Quartil 2 } \\
n=675\end{array}$ & $\begin{array}{c}\text { Quartil 3 } \\
n=883\end{array}$ & $\begin{array}{c}\text { Quartil 4 } \\
n=739\end{array}$ & $\begin{array}{c}\text { Geral } \\
n=2922\end{array}$ \\
\hline Contra $x$ a favor privatizações & & & & 0,41 & 0,39 \\
\hline A favor $x$ contra gastos sociais & 0,32 & 0,45 & 0,32 & 0,38 \\
\hline A favor $x$ contra reforma agrária & 0,34 & 0,45 & 0,45 & 0,51 & 0,43 \\
\hline Ajuda aos pobres $x$ construção de obras & & 0,33 & 0,51 & 0,48 & 0,40 \\
\hline $\begin{array}{l}\text { Combate desemprego } x \text { combate a } \\
\text { inflação }\end{array}$ & & 0,52 & & 0,47 & 0,36 \\
\hline Voz ao povo $x$ eficiência e rapidez & 0,31 & & 0,52 & 0,51 & 0,42 \\
\hline $\begin{array}{l}\text { Políticas focalizadas } x \text { crescimento } \\
\text { econômico }\end{array}$ & 0,45 & & 0,32 & 0,40 & 0,37 \\
\hline
\end{tabular}

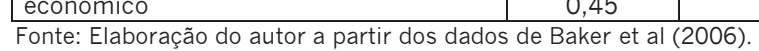

O modelo apresentado na Tabela 4 replica a análise feita por Delli Carpini e Keeter (1996) ${ }^{12}$. Os resultados parecem corroborar amplamente as considerações feitas anteriormente. Enquanto nos dois primeiros quartis apenas quatro variáveis carregam no fator, esse número aumenta para cinco no terceiro quartil, e, finalmente, inclui todas as sete variáveis no quartil com maior sofisticação política. Além disso, é possível observar que a magnitude das cargas fatoriais das variáveis tende a ser maior no último quartil em relação aos outros. É possível também notar que as cargas dos fatores não apresentam viés devido ao formato das questões. Essas são evidências fortes de que a conexão entre as atitudes aumenta conforme o nível de sofisticação política do respondente. Isso quer dizer que os respondentes mais sofisticados, uma vez que se baseiam nos mesmos eixos de considerações para formarem seus julgamentos, tendem a apresentar atitudes ou posições políticas ideologicamente parecidas em diferentes questões. Por outro lado, respondentes menos sofisticados orientam-se com menor frequência com base em considerações de natureza política e produzem padrões de respostas mais idiossincráticos.

11 A tabela omite as cargas fatoriais inferiores a 0,3 .

12 Há duas diferenças na análise feita aqui em relação ao estudo de Delli Carpini e Keeter. A primeira refere-se ao fato de que, aqui, utiliza-se a matriz de correlações policóricas entre os itens, e não a matriz de correlações de Pearson. A razão é que as primeiras são mais adequadas quando os itens ordinais ou binárias captam atributos latentes contínuos. A segunda diferença é o método de extração dos fatores. Aqui se usa o método de eixos principais, que gera cargas menores em relação ao método de componentes principais utilizado por Delli Carpini e Keeter. As justificativas para essas escolhas são discutidas no Apêndice. 


\section{BATISTA PEREIRA, F. Sofisticação política e opinião pública no Brasil: revisitando...}

Deixando de lado o tema da estruturação ideológica, cabe agora abordar o problema da estabilidade das atitudes políticas, ainda que, em certo sentido, sua estabilidade temporal também possa ser vista como manifestação de sua efetividade. Trata-se do caso em que a opinião em um ponto do tempo afeta a opinião sobre o mesmo assunto em algum tempo posterior. Ou seja, pode-se aferir a posição do indivíduo numa questão em um ponto do tempo caso se conheça sua posição anterior na mesma questão. $\mathrm{O}$ estudo de Converse também foi um marco em tratar desse tema. $\mathrm{O}$ autor verificou que a maioria das opiniões dadas pelos respondentes de sua pesquisa de painel apresentava alta instabilidade temporal, o que seria explicado pelo mesmo fator que explicava a falta de estruturação ideológica (CONVERSE, 1964, p. 241-243). O público seria dividido entre um núcleo de pessoas politicamente sofisticadas e portadoras de atitudes verdadeiras e a massa de indivíduos sem entendimento da política, e cujas atitudes oscilariam quase aleatoriamente.

O formato de painel da pesquisa aqui utilizada também possibilita realizar o teste da estabilidade temporal e examinar o efeito da sofisticação política. A Tabela 5 fornece as correlações entre algumas questões de opinião em três ondas da pesquisa ${ }^{13}$. Os indivíduos que não apareceram nas três ondas e os que não forneceram resposta em alguma questão foram descartados das análises. Aliás, vale mencionar que é a falta de respostas que faz com que o quartil menos sofisticado apresente menos casos nas análises temporais. Como se verá à frente, é o grupo menos sofisticado que apresenta maior taxa de não-resposta nas questões de opinião. As correlações utilizadas na Tabela 5 são do tipo tau-beta, o mesmo utilizado por Converse em seu estudo ${ }^{14}$ :

Tabela 5

Correlações Tau-B de Kendall entre os itens de opinião ao longo do tempo por quartil de sofisticação política em toda a amostra

\begin{tabular}{|l|c|c|c|c|c|c|}
\hline \multirow{2}{*}{ Questão } & Ondas da pesquisa & $\begin{array}{c}\text { Quartil 1 } \\
n=387\end{array}$ & $\begin{array}{c}\text { Quartil 2 } \\
n=506\end{array}$ & $\begin{array}{c}\text { Quartil 3 } \\
n=701\end{array}$ & $\begin{array}{c}\text { Quartil 4 } \\
n=625\end{array}$ & $\begin{array}{c}\text { Geral } \\
n=2219\end{array}$ \\
\hline \multirow{3}{*}{ Contra $x$ a favor privatizações } & abril $x$ setembro & 0,32 & 0,38 & 0,39 & 0,55 & 0,42 \\
\cline { 2 - 7 } & abril $x$ outubro & 0,38 & 0,39 & 0,43 & 0,52 & 0,44 \\
\cline { 2 - 7 } & setembro $x$ outubro & 0,54 & 0,48 & 0,50 & 0,59 & 0,53 \\
\hline $\begin{array}{l}\text { Contra } x \text { a favor livre } \\
\text { comércio }\end{array}$ & abril $x$ outubro & 0,22 & 0,18 & 0,18 & 0,31 & 0,23 \\
\hline \multirow{2}{*}{$\begin{array}{l}\text { A favor } x \text { contra gastos } \\
\text { sociais }\end{array}$} & abril $x$ setembro & 0,19 & 0,23 & 0,25 & 0,30 & 0,25 \\
\cline { 2 - 7 } & abril $x$ outubro & $0,09 *$ & 0,27 & 0,24 & 0,31 & 0,24 \\
\cline { 2 - 7 } & setembro $x$ outubro & 0,25 & 0,34 & 0,31 & 0,36 & 0,32 \\
\hline \multirow{2}{*}{$\begin{array}{l}\text { A favor } x \text { contra reforma } \\
\text { agrária }\end{array}$} & abril $x$ setembro & 0,32 & 0,45 & 0,38 & 0,41 & 0,40 \\
\cline { 2 - 7 } & abril $x$ outubro & 0,41 & 0,45 & 0,43 & 0,44 & 0,44 \\
\cline { 2 - 7 } & setembro $x$ outubro & 0,45 & 0,48 & 0,45 & 0,47 & 0,47 \\
\hline
\end{tabular}

* Apenas esta correlação foi estatisticamente significativa a 0,05 . Todas as demais foram a 0,01 . Fonte: Elaboração do autor a partir dos dados de Baker et al (2006).

O que se nota é que as correlações entre os itens de opinião ao longo do tempo são, em geral, baixas ou moderadas. Altas correlações indicam alta estabilidade. Assim como no estudo de Converse,

13 O item sobre a opinião em relação ao livre comércio não foi perguntado na onda de entrevistas feitas em setembro.

${ }^{14}$ Esse tipo de correlação parte da concepção forte em relação ao que seja a correlação, isto é, a concepção de monotonicidade perfeita (WEISBERG, 1974). Isso indica que o valor da estatística de correlação aumenta (aproxima-se de 1) na medida em aumenta a proporção de casos nos pares concordantes na tabela de contingência entre as duas variáveis cruzadas. Na medida em que a proporção de casos discordantes aumenta, a correlação tende a diminuir de valor (aproxima-se de -1). Os valores próximos de 0 indicam ausência de correlação. 
poucas correlações da Tabela 5 passam de 0,5. Todavia, o que se quer examinar aqui é se o aumento da estabilidade acompanha o aumento da sofisticação política. Alguns itens apresentam um aumento claro de estabilidade conforme se sobe nos quartis de sofisticação política, mas alguns apresentam padrões mais matizados. De todo modo, esses padrões mais matizados devem-se, em boa medida, ao fato de que o segundo e o terceiro quartis apresentam correlações muito parecidas, e que, em muitas vezes, chegam a ser maiores no quartil 2 do que no quartil 3. Todavia, o padrão mais geral da tabela parece incontestável: o bloco contendo os dois quartis intermediários apresenta correlações mais altas do que o primeiro quartil, enquanto o quartil superior apresenta as correlações mais altas da tabela.

Seja como for, é preciso discutir por que se deve esperar que os mais politicamente sofisticados mudem menos. Se, como foi argumentado anteriormente, a própria definição de sofisticação política contém a ideia de que os indivíduos mais sofisticados são mais capazes de reconhecer e responder aos estímulos do ambiente político, então, não seria de se esperar que também mudassem mais de opinião? Por que, ainda assim, os mais sofisticados politicamente mudam menos de opinião?

Os trabalhos de Zaller pretendem responder a essa pergunta (ZALLER, 1992; ZALLER \& FELDMAN, 1992). As pessoas teriam considerações armazenadas na memória a respeito de determinada questão política. Por considerações o(s) autor(es) compreende $(m)$ as razões que se tem para se favorecer a um ou a outro lado na questão (ZALLER, 1992, p. 40; ZALLER \& FELDMAN, 1992, p. 585). Todos os indivíduos portariam considerações conflitantes e ambíguas a respeito de questões políticas, e tomariam suas decisões em questões de survey com base nas considerações mais salientes no momento da pergunta. Assim:

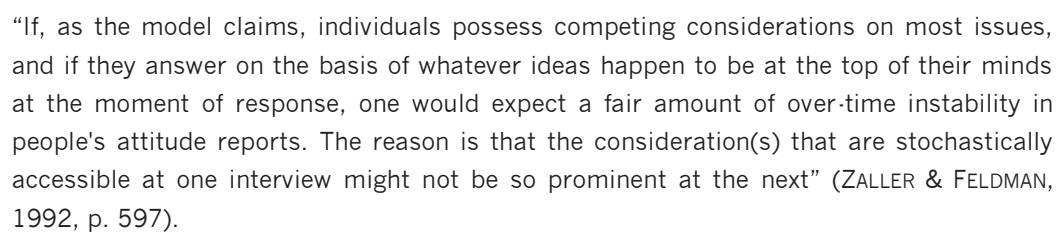

Até esse ponto, o modelo de Zaller (e Feldman) apenas provê o mecanismo que explica como as variações ambientais, ao proverem estímulos diversos e mudarem as considerações acessíveis aos indivíduos, produzem a mudança de opinião. Adicionalmente, o(s) autor(es) defende(m) que os mais sofisticados seriam mais estáveis devido ao maior número de considerações que já teriam armazenado. Nesse sentido,

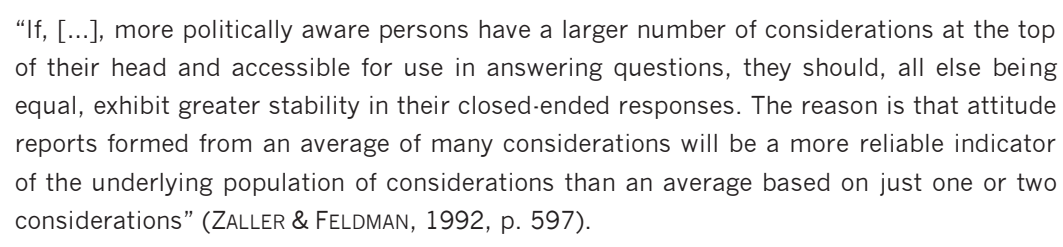
of their head and accessible for use in answering questions, they should, all else being equal, exhibit greater stability in their closed-ended responses. The reason is that attitude reports formed from an average of many considerations will be a more reliable indicator of the underlying population of considerations than an average based on just one or two considerations" (ZALLER \& FELDMAN, 1992, p. 597).

É com um modelo como esse que Zaller pretende dar conta da instabilidade nas opiniões detectada pelo estudo de Converse. Na verdade, o primeiro diferencia-se um pouco da abordagem desse último. Enquanto Converse divide o público entre os que têm atitudes "verdadeiras" e os que não 
BATISTA PEREIRA, F. Sofisticação política e opinião pública no Brasil: revisitando...

têm, Zaller sequer fala em atitudes "verdadeiras". Para este autor, a manifestação da atitude seria, na verdade, o vetor final da amostragem das considerações que o indivíduo portaria em relação à questão. Além do mais, Zaller argumenta que a direção do conjunto das considerações políticas dos mais sofisticados, o que justamente produziria a estabilidade em favor de uma ou outra direção, devia-se ao fato de que estes já possuiriam predisposições políticas. Para ele, os mais sofisticados tenderiam a resistir mais aos argumentos inconsistentes com suas atuais orientações políticas justamente porque teriam a habilidade ou as informações contextuais para perceberam as conexões dos estímulos com suas orientações políticas (ZALLER, 1992, p. 44).

Contudo, não se pode extrair das análises de Zaller a ideia de que os mais sofisticados simplesmente "tapariam os ouvidos" diante de informações novas e opostas às suas orientações políticas. A menor proporção de mudança de opinião entre os mais sofisticados teria a ver com o fato de que eles já teriam orientações prévias formadas com base em conjuntos mais amplos de considerações. Se o conceito de sofisticação denota a ideia de que o indivíduo sofisticado foi mais preparado por sua história de condicionamento para reconhecer os estímulos de natureza política, então, é inevitável concluir que os mais sofisticados sejam precisamente os que aprendem mais. Mais ainda, eles aprendem mais apesar das preferências que já têm.

Os dados utilizados aqui permitem testar o efeito da sofisticação sobre o aprendizado de "novos" estímulos levando-se em conta as preferências prévias dos indivíduos. Os respondentes foram perguntados em abril e em outubro sobre os nomes de candidatos a presidente, governador e senador que conheciam. Para criar uma variável que representasse o ganho de informação dos indivíduos no período entre abril e outubro - o período mais movimentado do ponto de vista político-eleitoral - foram feitos os somatórios dos nomes de candidatos que o respondente foi capaz de citar em abril e em outubro ${ }^{15}$, e depois se diminuiu o escore de abril do escore de outubro. Essa variável seria uma aproximação da quantidade de informações que o respondente adquiriu a respeito da disputa eleitoral no período. Obviamente, foram selecionados para a análise apenas os casos que se repetiam em abril e outubro. A Tabela 6 apresenta os resultados de modelos de regressão ajustados tendo como variável dependente o nível de ganho informacional:

${ }^{15}$ Não se levou em conta nomes de pré-candidatos que apareceram na disputa pré-eleitoral em abril e não mais apareceram em outubro. Um caso desse tipo foi o de Roseana Sarney, candidata à Presidência em abril e saiu da disputa algum tempo depois. 
Tabela 6

Regressões lineares tendo como variável dependente o ganho informacional para toda a amostra

\begin{tabular}{|c|c|c|c|}
\hline & Modelo 1 & Modelo 2 & Modelo 3 \\
\hline Variáveis independentes & $\begin{array}{c}\text { Coeficiente não } \\
\text { padronizado } \\
\text { (Erro Padrão) }\end{array}$ & $\begin{array}{c}\text { Coeficiente não } \\
\text { padronizado } \\
\text { (Erro Padrão) }\end{array}$ & $\begin{array}{c}\text { Coeficiente não } \\
\text { padronizado } \\
\text { (Erro Padrão) }\end{array}$ \\
\hline Intercepto & $\begin{array}{l}4,29 * * * * \\
(0,12)\end{array}$ & $\begin{array}{l}3,91^{* * * *} \\
(0,14)\end{array}$ & $\begin{array}{c}4,09 * * * \\
(0,19)\end{array}$ \\
\hline Sofisticação & $\begin{array}{l}0,37^{* * * *} \\
(0,03)\end{array}$ & $\begin{array}{l}0,83^{* * * *} \\
(0,10)\end{array}$ & $\begin{array}{l}1,01^{* * *} \\
(0,10)\end{array}$ \\
\hline Cidade (Juiz de Fora $=0$ ) & $\begin{array}{c}1,06^{* * *} \\
(0,11)\end{array}$ & $\begin{array}{l}0,98 * * * \\
(0,11)\end{array}$ & $\begin{array}{l}1,32^{* * * *} \\
(0,12)\end{array}$ \\
\hline Sofisticação*Sofisticação & - & $\begin{array}{l}-0,08 * * * \\
(0,02)\end{array}$ & $\begin{array}{l}-0,06 * * * \\
(0,02)\end{array}$ \\
\hline $\begin{array}{l}\text { Número de candidatos } \\
\text { conhecidos em abril }\end{array}$ & . & . & $\begin{array}{l}-0,41^{* * *} \\
(0,03)\end{array}$ \\
\hline $\begin{array}{l}\text { Possuía identificação partidária } \\
\text { em abril (Não = 0) }\end{array}$ & - & - & $\begin{array}{l}0,06 \\
(0,11)\end{array}$ \\
\hline $\begin{array}{c}\text { Possuía autolocalização } \\
\text { ideológica em abril (Não = 0) }\end{array}$ & $\cdot$ & - & $\begin{array}{l}-0,13 \\
(0,12)\end{array}$ \\
\hline $\begin{array}{c}\text { Possuía candidato a presidente } \\
\text { em abril }(\text { Não }=0)\end{array}$ & $\cdot$ & . & $\begin{array}{l}0,05 \\
(0,15)\end{array}$ \\
\hline $\begin{array}{c}\text { Possuía candidato a governador } \\
\text { em abril }(\text { Não }=0)\end{array}$ & . & . & $\begin{array}{l}-0,11 \\
(0,15)\end{array}$ \\
\hline$n$ & 3443 & 3443 & 3443 \\
\hline $\mathrm{R}^{2}$ Ajustado & 0,07 & 0,07 & 0,12 \\
\hline Teste F & $126,1 * * *$ & $92,8 * * *$ & $56,7^{* * *}$ \\
\hline
\end{tabular}

*** Estatisticamente significativo a 0,01.

O primeiro modelo parte da suposição de que apenas dois fatores afetam linearmente o ganho informacional: a sofisticação política do respondente e o ambiente eleitoral no qual este se encontra no caso, cada cidade analisada. O resultado indica uma associação fraca entre sofisticação e aprendizado, já que, para cada ponto de sofisticação que se tem em abril, aprende-se aproximadamente 0,3 nomes de políticos a mais em outubro. Também se pode concluir que Caxias do Sul é um ambiente onde se aprende mais do que Juiz de Fora ${ }^{16}$. A leitura desse modelo pode ser facilitada pelo exame da Figura 1, que cruza os valores simulados de ganho informacional com o nível de sofisticação do respondente. Nota-se que a associação linear entre ganho informacional e sofisticação política é fraca no modelo 1 , o que revela que talvez sejam necessárias mais especificações. É precisamente pela falta de especificações que o modelo não chega a testar diretamente a hipótese levantada antes.

16 O que corrobora as observações de Rennó (2004). 
Figura 1

Modelo 1 da Tabela 6: valores simulados de ganho informacional por nível de sofisticação política

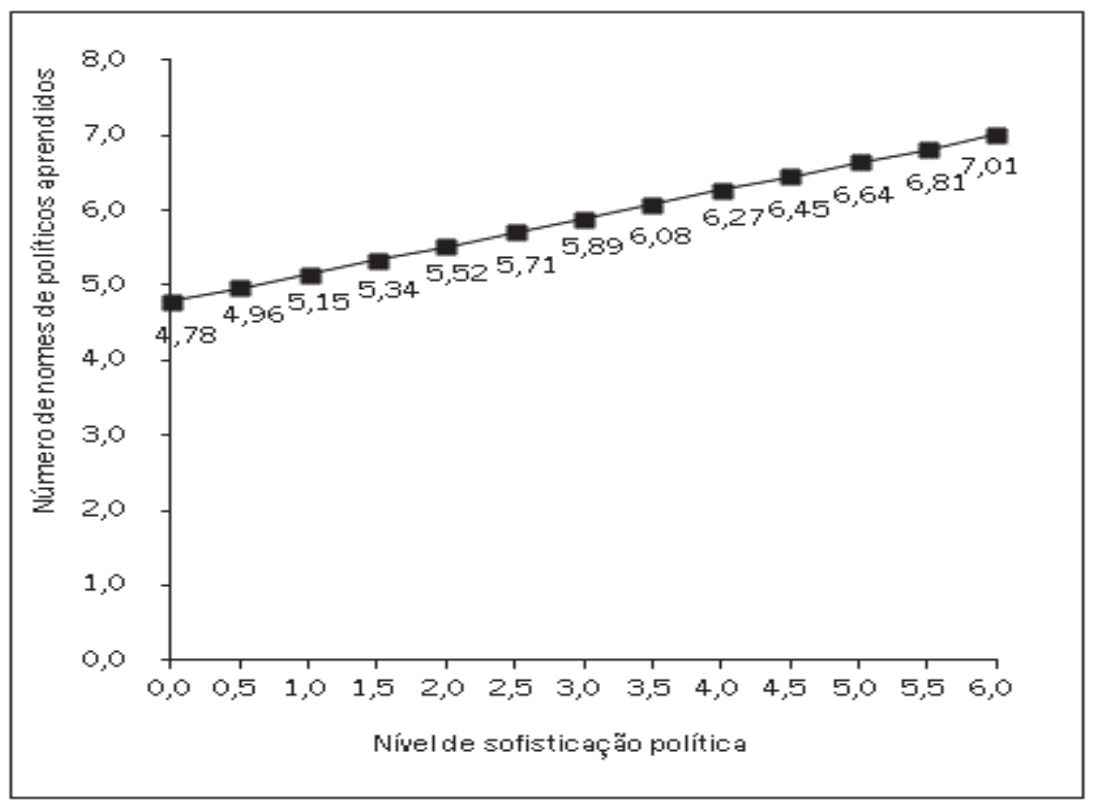

Fonte: Elaboração do autor a partir dos dados de Baker et al (2006).

O modelo 2 da Tabela 6 mantém as mesmas variáveis do modelo 1 e inclui um termo quadrático, isto é, um termo multiplicativo entre a variável de sofisticação política e ela mesma (Sofisticação*Sofisticação). O que esse termo quadrático permite é testar a hipótese condicional sobre se o efeito da sofisticação sobre o ganho informacional aumenta, diminui ou permanece o mesmo quanto mais sofisticado é o respondente. Ou seja, ele testa justamente se os mais sofisticados ganham mais do que os menos sofisticados. O resultado parece corroborar parcialmente essa hipótese. Como se vê, o termo quadrático tem um efeito negativo, indicando que, atingido certo nível no escore de sofisticação política, não há mais ganho informacional em relação aos níveis medianos de sofisticação. No entanto, o efeito de compensação não é forte o suficiente para evidenciar que o respondente mais sofisticado ganhe menos informação do que o respondente menos sofisticado. Outro ponto a ser notado é o aumento no coeficiente da variável de sofisticação política. A interpretação desses resultados é facilitada pelo exame da Figura 2, que também cruza o ganho informacional com o nível de sofisticação política, agora no modelo que controla seu efeito pelo termo quadrático. 
Figura 2

Modelo 2 da Tabela 6: valores simulados de ganho informacional por nível de sofisticação política

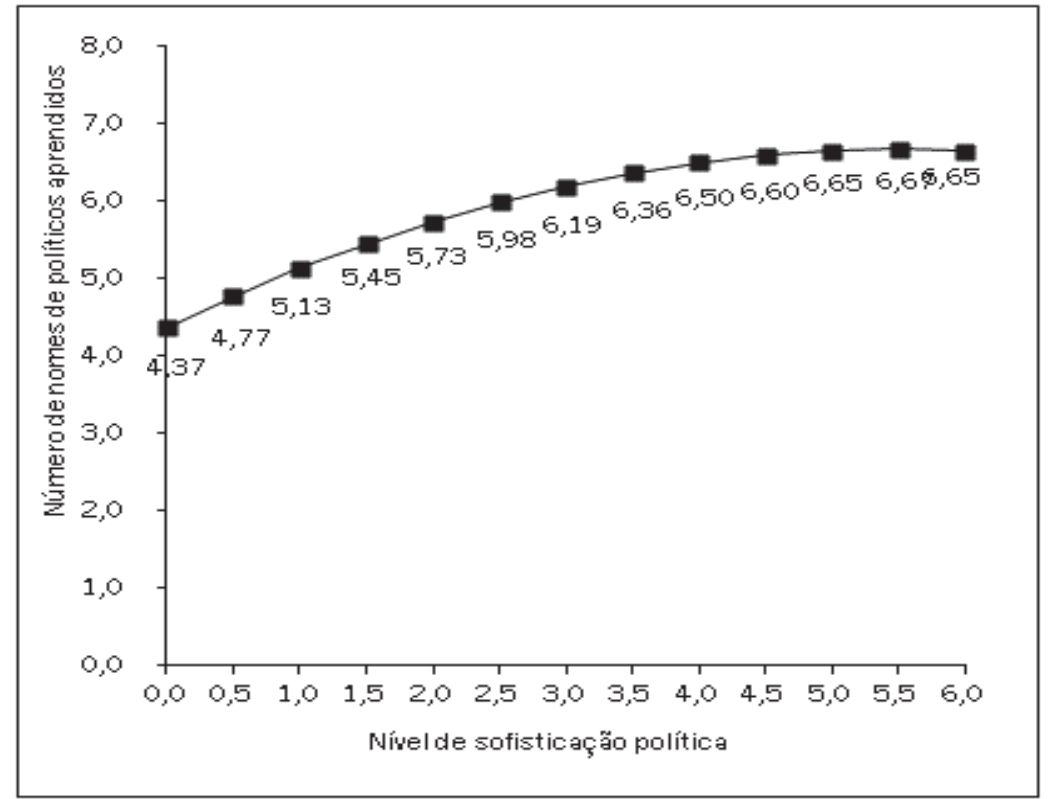

Fonte: Elaboração do autor a partir dos dados de Baker et al (2006).

Todavia, o modelo 2 ainda requer especificações para se testar por completo a hipótese aventada anteriormente. Por que os mais sofisticados não aprendem mais do que os respondentes mais próximos da mediana no escore de sofisticação? Ou seja, por que o efeito da sofisticação política sobre o ganho informacional não é linear? O modelo 3 aborda essa pergunta com maior precisão. Um bloco de variáveis o de variáveis da pesquisa pode ser usado para representar as preferências prévias dos respondentes em abril. Nesse bloco, aparecem quatro variáveis binárias que indicam se o respondente já possuía identificação partidária, se já possuía identificação ideológica, se já tinha candidatos a governador e a presidente em abril17. A inserção desse bloco de variáveis no modelo testa a hipótese de que os mais sofisticados, por já possuírem orientações prévias, "tapariam os ouvidos" em relação aos novos estímulos políticos. Para corroborar essa hipótese, espera-se que a inflexão da curva (causada pelo termo quadrático) desapareça, e que pelo menos alguma dessas variáveis tenha efeito negativo.

A variável que testa a hipótese concorrente no modelo 3 consiste no número de candidatos que o respondente já sabia dizer em abril. Essa variável certamente apresentará um efeito negativo, uma vez que está subtraída na variável dependente. No entanto, o que importa aqui é saber se sua inclusão no modelo causa uma diminuição ou mesmo o desaparecimento da inflexão da curva. Nesse caso, será possível dizer que os mais sofisticados deixam de ganhar mais do que os outros (os medianamente sofisticados) por conta do que já têm, e não porque "tapam os ouvidos".

17 Não foi perguntado na pesquisa se o respondente já havia escolhido seu candidato a senador em abril. 


\section{BATISTA PEREIRA, F. Sofisticação política e opinião pública no Brasil: revisitando...}

Os resultados do modelo 3 refutam claramente a hipótese de que as predisposições fazem com que os indivíduos politicamente mais sofisticados aprendam menos do que se esperaria. Nota-se que o efeito do termo quadrático cai, indicando redução na inflexão da curva, e o efeito isolado da sofisticação política aumenta para quase 1 ponto. As variáveis indicando as preferências prévias apresentam coeficientes muito fracos, alguns chegando a ser positivos, contrariamente ao que se esperava. A variável que indica o número de candidatos que o respondente já conhecia em abril apresenta o efeito negativo que já se esperava observar. A cada candidato já conhecido em abril o aprendizado de nomes novos em outubro diminui em 0,4. A Figura 3 mostra como a inflexão da curva praticamente se neutraliza e o efeito da sofisticação volta a ser quase linear, isto é, ele permanece relativamente alto mesmo para os níveis mais elevados de sofisticação. Os sofisticados aprendem mais quando se leva em conta o que já sabiam.

Figura 3

Modelo 3 da Tabela 6: valores simulados de ganho informacional

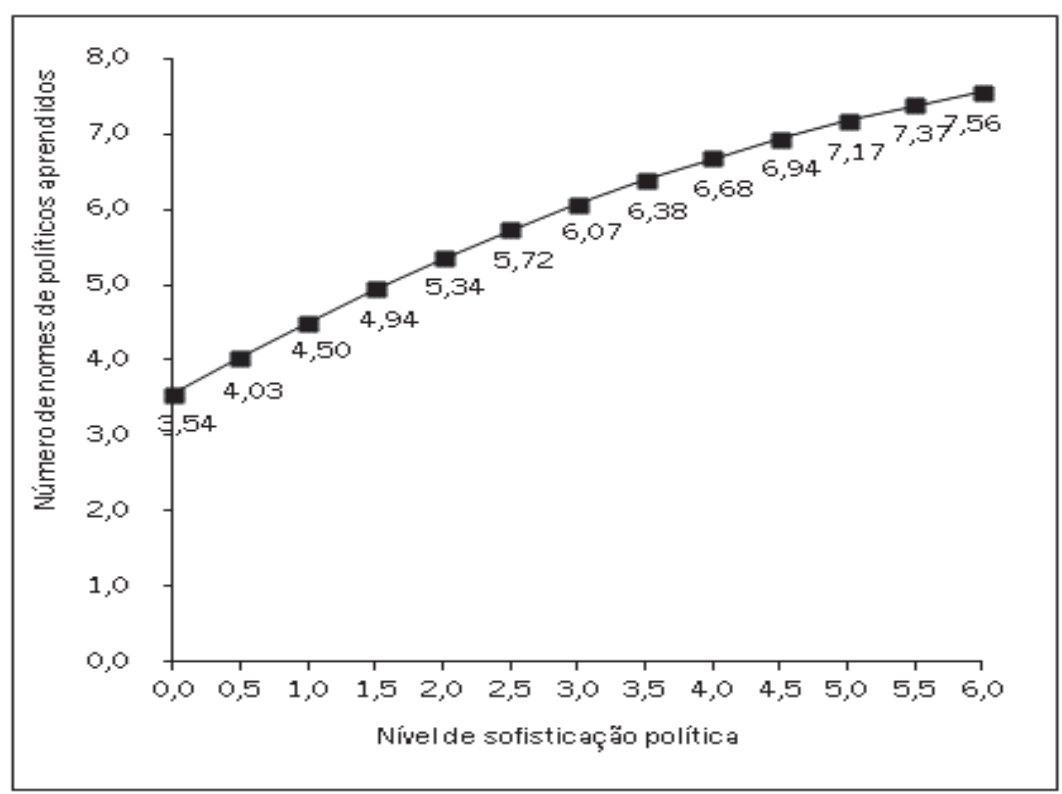

Fonte: Elaboração do autor a partir dos dados de Baker et al (2006).

A explicação do fato de que os politicamente mais sofisticados sejam os mais estáveis mesmo sendo os mais sensíveis às variações nos estímulos ambientais reside precisamente em que as atitudes que já possuem impactam a maneira como recebem as novas informações. Essas atitudes foram formadas por meio de um processo no qual foram reforçadas contínua e intensamente ao longo do tempo. As atitudes pré-existentes que caracterizam o processamento de novas informações dos mais sofisticados formaram-se pelo estoque de estímulos favoráveis a elas. Para Zaller, esse processo resulta em um acúmulo de considerações que tende a favorecer um lado da escolha em detrimento do outro, de modo que as novas considerações favoráveis ao segundo nem sempre são suficientes para alterar o balanço do total de considerações em favor do primeiro. É por essa razão que os mais sofisticados 
captam estímulos novos e, ao mesmo tempo, são capazes de manter sua posição, já que foram recorrente e intensamente reforçados a tê-la no tempo e no espaço.

É possível reforçar esse argumento mostrando que os indivíduos mais sofisticados tendem a expressar mais orientações políticas do que os outros. A Tabela 7 apresenta as proporções de opiniões emitidas por cada quartil de sofisticação política em algumas questões de opinião e preferência política em outubro:

Tabela 7

Percentual de preferências emitidas por quartil de sofisticação política em toda a amostra

\begin{tabular}{|l|c|c|c|c|c|}
\hline \multicolumn{1}{|c|}{ Questão } & $\begin{array}{c}\text { Quartil 1 } \\
\mathrm{n}=1219\end{array}$ & $\begin{array}{c}\text { Quartil 2 } \\
\mathrm{n}=1109\end{array}$ & $\begin{array}{c}\text { Quartil 3 } \\
\mathrm{n}=1410\end{array}$ & $\begin{array}{c}\text { Quartil 4 } \\
\mathrm{n}=1144\end{array}$ & $\begin{array}{c}\text { Geral } \\
\mathrm{n}=4882\end{array}$ \\
\hline Tem identificação partidária & 40,03 & 51,58 & 51,42 & 58,13 & 50,18 \\
\hline Tem identificação ideológica & 44,54 & 60,60 & 70,43 & 82,60 & 64,58 \\
\hline Opina sobre privatizações & 80,97 & 92,97 & 96,52 & 98,25 & 92,24 \\
\hline Opina sobre livre comércio & 87,03 & 96,12 & 98,09 & 99,48 & 95,21 \\
\hline Opina sobre gastos sociais & 91,06 & 98,29 & 97,56 & 97,03 & 95,99 \\
\hline Opina sobre reforma agrária & 91,30 & 97,48 & 98,06 & 98,34 & 96,31 \\
\hline Tem candidato a presidente & 73,50 & 79,26 & 77,16 & 81,90 & 77,84 \\
\hline Tem candidato a governador & \multicolumn{2}{|c|}{72,27} \\
\hline
\end{tabular}

Embora as perguntas sobre assuntos como privatizações, livre comércio, gastos sociais e reforma agrária apresentem níveis gerais elevados de "opinação", ainda é possível notar que a proporção de respostas tende a aumentar linearmente conforme aumenta o nível de sofisticação política. No item referido à opinião sobre as privatizações, a diferença chega a ser de 18 pontos percentuais entre o último e o primeiro quartil. Todavia, essas questões certamente tendem a ser menos centrais nos sistemas de crenças do que a autolocalização ideológica e a identificação partidária. Com isso se quer dizer que essas duas preferências, entre os indivíduos que as portam, provavelmente têm impacto maior sobre comportamentos e até mesmo sobre outras opiniões. É em relação a essas duas atitudes que as diferenças entre os mais sofisticados e os menos sofisticados mostram-se mais claras. A identificação partidária apresenta baixas proporções de respostas e a diferença do último para o primeiro quartil chega a 18 pontos percentuais. A diferença é bem maior no caso da chamada "identificação ideológica", para a qual essa diferença chega a quase 40 pontos percentuais. As questões sobre as preferências por presidente e governador em abril apresentam níveis intermediários de opinação, mas também mostram padrões lineares de aumento na medida em que se aumenta o nível de sofisticação política dos respondentes.

Toda essa argumentação, por outro lado, não autoriza dizer que os mais sofisticados resistem ao ponto de não mudarem em nenhuma circunstância suas opiniões. As orientações prévias, por mais fortes que sejam, sempre podem ser modificadas por estímulos novos. Estímulos tendem a ser vistos como "informações novas" com mais frequência por indivíduos menos sofisticados que, por definição, são menos treinados a reconhecer os estímulos políticos, do que por indivíduos mais sofisticados. 
BATISTA PEREIRA, F. Sofisticação política e opinião pública no Brasil: revisitando...

\section{Considerações Finais}

A partir da discussão sobre o conceito e a mensuração da sofisticação política, este artigo utilizou dados de pesquisa de opinião em painel para testar quatro hipóteses clássicas a respeito do impacto da desigualdade de sofisticação política nas opiniões dos cidadãos. Os resultados das análises mostraram, corroborando a teorização sobre o tópico, que: 1) as opiniões dos cidadãos mais sofisticados tendem a ser mais ideologicamente articuladas do que as dos menos sofisticados; 2) cidadãos mais sofisticados têm opiniões políticas mais estáveis ao longo do tempo; 3) cidadãos politicamente mais sofisticados adquirem mais informações do que os menos sofisticados ao longo do processo eleitoral, e; 4) os cidadãos mais sofisticados tendem a expressar mais opiniões do que os menos sofisticados.

Reitera-se, portanto, a importância de se levar em conta a desigualdade de sofisticação política entre os eleitores nas análises e interpretações da dinâmica da opinião pública no sistema político. No Brasil, parece ainda haver vacilações por parte de estudiosos de opinião pública com relação ao significado e às implicações do conceito aqui discutido. Mais especificamente, do ponto de vista normativo, o conceito de sofisticação política parece ser ainda evitado por conta de certas conotações que parece evocar. Um exercício interessante é o de esclarecer três delas em especial:

1. Baixa sofisticação política não denota automaticamente incompetência ou incapacidade de participar e opinar sobre política. Certamente, indivíduos mais sofisticados com relação a determinado assunto possuem mais chances de obter sucesso e satisfação com suas escolhas do que indivíduos menos informados ou sofisticados. Entretanto, ser pouco sofisticado em determinado assunto não impede que se seja bem sucedido nas escolhas. Isso se deve ao fato de que escolhas são feitas em contextos e que, portanto, as características destes podem influenciar as chances de alguém ser bem sucedido em uma escolha. Certas circunstâncias facilitam as escolhas dos agentes, outras atrapalham. Em contextos mais complexos, os indivíduos menos sofisticados tendem a ser os mais prejudicados.

2. O termo sofisticação deve ser sempre acompanhado de um complemento que o remeta ao domínio simbólico da "política". Quando se fala em sofisticação política nos estudos de comportamento eleitoral e opinião pública, faz-se referência à complexidade das considerações que o indivíduo carrega quando o assunto envolve os fatos, objetos e conceitos da política. É possível que um cidadão seja extremamente sofisticado em assuntos que não têm absolutamente nada a ver com política e, ao mesmo tempo, seja completamente alheio ao que se passa no governo e na prefeitura, por exemplo. A sofisticação é um conceito aplicável a qualquer domínio simbólico no qual se dá a ação humana. Portanto, ao se dizer que determinados indivíduos são politicamente menos sofisticados do que outros, não se pretende dizer que o sejam para todas as outras coisas que realizam, isto é, que sejam ignorantes de uma maneira geral.

3. Sofisticação política não é o mesmo que ideologia, apesar da existência de certa conexão entre os dois conceitos. Dizer que um cidadão é politicamente sofisticado não é o mesmo que dizer que ele possui uma ideologia definida ou que, necessariamente, tem preferência por algum partido. Tal ponto foi suficientemente esclarecido na seção do artigo que discutiu o conceito de sofisticação.

Por fim, os resultados expostos neste artigo mostram que a chamada "tese minimalista", cuja paternidade foi atribuída a Converse e se referiria aos baixos níveis de informação política e 
estruturação ideológica dos eleitores estadunidenses, contribui menos como uma denúncia da incapacidade das massas para a política e mais como um diagnóstico da desigualdade política presente mesmo em democracias mais desenvolvidas e estáveis. Nesse sentido, parece crucial considerar que essa desigualdade tenha impacto sobre a maneira como os eleitores brasileiros tomam suas decisões na política.

\section{Referências Bibliográficas}

ACHEN, C. "Mass political attitudes and the survey response". The American Political Science Review, 69, p.1218-1231, 1975.

Baker, A.; Ames, B.; Rennó, L. "Social Context and Campaign Volatility in New Democracies: Networks and Neighborhoods in Brazil's 2002 Elections”. American Journal of Political Science, 50 (2), p. 382.399, 2006.

BAKER, F. The Basics of Item Response Theory. Baltimore: Eric Clearinghouse on Assessment and Evaluation, 2001.

BIRnBaum, A. Some Latent Trait Models and Their Use in Inferring an Examinee's Ability. In: LORD, F. M.; NoviCK, M. R. (eds.). Statistical Theories of Mental Test Scores. Reading, Addison-Wesley, p. 397-472, 1968.

BRAMBOR, T.; CLARK, W.; Golder, M. "Understanding Interaction Models: Improving Empirical Analyses". Political Analysis, 14, p. 63.82, 2006.

Campbell, A.; Converse, P.; Miller, W.; Stokes, D. The American Voter. New York: John Wiley, 1960.

CASTRO, M. M. M. "Determinantes do Comportamento Eleitoral: a centralidade da sofisticação política”. Rio de Janeiro, Tese de Doutorado, IUPERJ, 1994.

Converse, P. The Nature of Belief Systems in Mass Publics. In: Apter, D. (ed.). Ideology and Discontent. New York: Free Press, p. 206-261, 1964.

Costello, A.; Osborne, J. "Best Practices in Exploratory Factor Analysis: Four Recommendations for Getting the Most From Your Analysis". Practical Assessment, Research \& Evaluation, 10 (7), p. 1.9, 2005.

Delli Carpini, M.; Keeter, S. What Americans Know About Politics and Why It Matters. New Heaven: Yale University Press, 1996.

FUKS, M.; BATISTA PEREIRA, F. "Informação e conceituação: a dimensão cognitiva da desigualdade política entre jovens de Belo Horizonte". Revista Brasileira de Ciências Sociais, 26 (76), p. 123-143, 2011.

IMAI, K.; KING, G.; LAU, O. "Toward A Common Framework for Statistical Analysis". Journal of Computational and Graphical Statistics, 17 (4), p. 892-913, 2008.

Acesso em: 16 mar. 2010.

JUDD, C.; MILBURN, M. "The structure of attitude systems in the general public: Comparisons of a structural equation model". American Sociological Review, 45, p. 627-643, 1980.

KIM, J. \& Mueller, C. Factor Analysis: Statistical Methods and Practical Issues. Beverly Hills: Sage Publications, 1978.

KING, G.; Tomz, M.; WitTenberG, J. "Making the Most of Statistical Analysis: Improving Interpretation and Presentation". American Journal of Political Science, 44 (2), p. 341-355, 2000.

KUKLINSKI, J.; QUIRK, P. “Conceptual Foundations of Citizen Competence”. Political Behavior, 23 (3), p. 285-311, 2002.

Krosnick, J.; RAHN, W. Attitude Strength. Encyclopedia of Human Behavior, 1, p. 279.289, 1994.

LAmounier, B. Comportamento Eleitoral em São Paulo: Passado e Presente. In: Lamounier, B.; CARdoso, F. H. (orgs.). Os Partidos e as Eleições no Brasil. Rio de Janeiro: Paz e Terra, p. 15.44, 1975. 


\section{BATISTA PEREIRA, F. Sofisticação política e opinião pública no Brasil: revisitando...}

Presidente Prudente: o Crescimento da Oposição num Reduto Arenista. In: REIS, F. W. (org.). Os Partidos e o Regime: A lógica do processo eleitoral brasileiro. São Paulo: Edições Símbolo, p. 1.89, 1978.

O Voto em São Paulo: 1970-1978. In: LAmounier, B. (org.). Voto de Desconfiança: eleições e mudança política no Brasil: 1970-1979. São Paulo: Vozes, p. 15·80, 1980

LUSkIN, R. “Measuring Political Sophistication”. American Journal of Political Science, 31 (4), p. 856.899, 1987.

“Explaining Political Sophistication". Political Behavior, 12 (4), p. 331-361, 1990.

Neuman, W. R. "Differentiation and Integration: Two Dimensions of Political Thinking". The American Journal of Sociology. 86 (6), p. 1236-1268, 1981.

The Paradox of Mass Politics: Knowledge and Opinion in the American Electorate. Cambridge: Harvard University Press, 1986.

Nie, N.; Verba, S.; Petrocik, J. The Changing American Voter. Cambridge: Harvard University Press, 1976.

Niemi, R. \& Junn, J. Civic Education: What Makes Students Learn. New Haven: Yale University Press, 1998.

Nunnally, J. Psychometric Theory. New York: McGraw-Hill, 1978.

OSTeRLIND, S. Test Item Bias. Newbury Park: Sage Publications, 1983

ReIS, F. W. Classe Social e Opção Partidária: Eleições de 1976 em Juiz de Fora. In: REIS, F. W. (org.). Os Partidos e o Regime: A lógica do processo eleitoral brasileiro. São Paulo: Edições Símbolo, p. 213.287, 1978.

Identidade, Política e Teoria da Escolha Racional. In: Mercado e Utopia: Teoria Política e Sociedade Brasileira. São Paulo: Edusp, p. 63.82, 2000.

1992

; CAStro, M. M. M. “Regiões, Classe e Ideologia no Processo Eleitoral Brasileiro". Lua Nova, 26, p. 81-131,

RenNó, L. Information and Voting: Microfoundations of Accountability in Complex Electoral Environments. Pittsburgh, Tese de Doutorado. University of Pittsburgh, 2004.

"Os militantes são mais informados? Desigualdade e informação política nas eleições de 2002". Opinião Pública, vol, 12, n², p. 329-347, 2006.

“Desigualdade e Informação Política: As Eleições Brasileiras de 2002". Dados, 50 (4), p. 721.755, 2007.

Rizopoulos, D. "Itm: An R Package for Latent Variable Modeling and Item Response Theory Analyses". Journal of Statistical Software, 17 (5), p. 1·25, 2006.

Sniderman, P.; Brody, R.; Tetlock, P. Reasoning and Choice: Explorations in Political Psychology. New York: Cambridge University Press, 1991

Sullivan, J.; Piereson, J.; Marcus, G. "Ideological Constraint in Mass Publics: A Methodological Critique and Some New Findings". American Journal of Political Science, 22 (2), p. 333-349, 1978.

Stimson, J. "Belief Systems: Constraint, Complexity, and the 1972 Election". American Journal of Political Science, 19 (3), p. 394-417, 1975

TURGEON, M.; RENNÓ, L. "Informação política e atitudes sobre gastos governamentais e impostos no Brasil: evidências a partir de um experimento de opinião pública". Opinião Pública, vol. 16, n 1, p. 143-159, 2010.

WeIsberg, H. "Models of Statistical Relationship". The American Political Science Review, 68 (4), p. 1638-1655, 1974.

Zaller, J. The Nature and Origins of Mass Opinion. New York: Cambridge University Press, 1992.

-Feldman, S. "A Simple Theory of Survey Response: Answering Questions versus Revealing Preferences". American Journal of Political Science, 36 (3), p. 579.616, 1992.

Zeller, R. \& Carmines, E. Measurement in the Social Sciences: The Link Between Theory and Data. Cambridge: Cambridge University Press, 1980. 


\section{Apêndice}

Este apêndice discute os procedimentos de construção das escalas utilizadas no artigo. Como escalas foram avaliadas e elaboradas por meio de técnicas similares, as técnicas são discutidas e seus resultados descritos de forma mais detalhada apenas para o construto de sofisticação política.

\section{Sofisticação política}

A sofisticação política é um construto contínuo, isto é, uma habilidade que os indivíduos possuem em maior ou menor grau. A sofisticação também é uma habilidade latente em relação às questões de conhecimento perguntadas nas pesquisas. Nesse sentido, é possível conceber essas baterias de questões que visam captar o mesmo atributo latente como sendo um teste, uma tentativa de estimar uma habilidade ou característica contínua latente dos indivíduos por meio de um conjunto de questões que eles respondem ${ }^{18}$. A Teoria Clássica do Teste (TCT) assume que o escore em uma questão como essas é o resultado da soma do escore verdadeiro, isto é, a habilidade que a questão busca captar, com os erros de mensuração (ZELLER \& CARMINES, 1980, p. 7). Essa formulação indica a possibilidade de que certos itens sejam melhores do que outros em captar o construto latente que se quer medir. Então, ao simplesmente somar as questões e compor uma escala aditiva, corre-se o risco de levar em conta tanto a habilidade "verdadeira" que se quer captar quanto os erros de mensuração de cada questão.

A Análise Fatorial tenta minimizar esse problema captando apenas a variância compartilhada pelas questões. Esse procedimento verifica o quanto cada variável contribui para dimensões latentes calculadas a partir das combinações de associações lineares entre as variáveis (KIM \& MUELLER, 1978, p. 8). Do ponto de vista da Teoria Clássica do Teste, a utilização desta técnica parte do seguinte raciocínio: imagine que três questões $(A, B$ e $C$ ) foram feitas para captar a variação de um dado atributo ( $T$ ). O desempenho de um mesmo conjunto de respondentes nas três questões pode ser representado pela equação $X_{i}=T+e_{i}$, onde $i$ representa cada item. Sendo assim, toda a variação que é comum a $A, B$ e $C$ corresponde a $T$, o atributo que se quer medir, e a proporção de variância que cada questão não compartilha com as demais corresponde aos erros de mensuração $e_{i}$. Portanto, a Análise Fatorial permite testar essas suposições quanto às baterias de questões. No entanto, é comum encontrar certos equívocos entre os trabalhos que lançam mão desta técnica. O principal deles é o de utilizar a extração por Componentes Principais ao invés da extração por Eixos Principais. A primeira calcula a carga fatorial, isto é, o peso de cada variável sobre o fator latente, com base no quanto cada item contribui para a variância total do conjunto das variáveis (o que faz com que esse método produza, em geral, cargas fatoriais muito mais altas do que os outros). O segundo tipo de extração computa essas cargas com base no quanto cada item contribui apenas para a variância compartilhada entre os itens, isto é, o próprio atributo latente $T$ (COSTELlo \& OSBORNE, 2005, p. 2). Não faz sentido, portanto, calcular as cargas com base em toda a variância de cada variável, mas apenas na variância que os itens compartilham.

18 O fraseado e as opções de respostas das questões de informações políticas utilizadas aqui são fornecidas na Tabela 1 do artigo. 


\section{BATISTA PEREIRA, F. Sofisticação política e opinião pública no Brasil: revisitando...}

A Tabela A1 apresenta o resultado da Análise Fatorial por Eixos Principais entre os itens de sofisticação política, calculada a partir da matriz de correlações tetracóricas entre os itens. Como os itens são binários, utilizam-se as correlações tetracóricas (ou policóricas, em caso de itens ordinais), que são mais apropriadas para se captar a associação entre itens binários (ou ordinais) que medem construtos latentes contínuos.

Tabela A1

Análise Fatorial por Eixos Principais sem rotação dos itens de sofisticação política

\begin{tabular}{|l|c|}
\hline \multirow{2}{*}{\multicolumn{1}{|c|}{ Itens }} & Cargas Fatoriais \\
\cline { 2 - 2 } & Fator 1 \\
\hline Vice-presidente & 0,87 \\
\hline Partido de FHC & 0,76 \\
\hline País do MERCOSUL & 0,75 \\
\hline Presidente da Câmara & 0,76 \\
\hline Corso/Delgado & 0,7 \\
\hline Senador & 0,81 \\
\hline
\end{tabular}

Alphade Cronbach $=0.80$

Fonte: Elaboração do autor a partir dos dados de Baker et al (2006).

A análise mostra que é possível aferir a existência de uma única dimensão latente entre os itens: a sofisticação política. O Alpha de Cronbach é um indicador único de confiabilidade e dimensionalidade para baterias de questões que buscam medir o mesmo atributo latente. Ele é utilizado paralelamente à Análise Fatorial, e varia de 0 a 1, sendo que valores acima de 0.6 são considerados bons.

Entretanto, a Análise Fatorial é apenas um teste de dimensionalidade. Seria possível salvar o fator como uma variável contínua capaz de discriminar os pesos das respostas em cada item com base nas cargas, o que aumentaria o número de pontos na escala, levando também ao aumento da variabilidade no construto. Porém, o modelo fatorial tende a produzir cargas mais baixas para itens com distribuição muito assimétrica (DelLI CARPINI \& KeETER, 1996, p. 297; NUNNALLY, 1978, p. 140). Sendo assim, itens de conhecimento muito fáceis ou muito difíceis podem ter sua influência subestimada no fator final por conta de sua baixa variabilidade. Além disso, o modelo de Análise Fatorial busca explicar a covariância entre os itens, e não a variância de cada item.

A técnica que tem sido cada vez mais utilizada nas Ciências Sociais para construir escalas como a elaborada aqui é a Teoria de Resposta ao Item ou TRI (BIRNBAUM, 1968; BAKER, 2001; OSTERLIND, 1983). Em linhas gerais, a TRI propõe que o desempenho do respondente em uma questão de teste depende de dois fatores principais: a dificuldade da questão e a habilidade que o respondente possui para respondê-la. É possível modelar essa formulação para itens binários, produzindo o que se chama de modelo logístico de dois parâmetros (dificuldade e discriminação). Essa técnica possibilita analisar o desempenho dos itens e calcular o seu peso no construto latente levando-se em conta tanto sua capacidade de discriminação quanto seu nível de dificuldade. A Tabela A2 apresenta os coeficientes do modelo logístico de dois parâmetros por máxima verossimilhança para cada item de informação: 
Tabela A2

Modelo logístico de dois parâmetros (TRI) para os itens de sofisticação política

\begin{tabular}{|l|c|c|}
\hline \multicolumn{1}{|c|}{ Itens } & Parâmetro de dificuldade & Parâmetro de discriminação \\
\hline Vice-presidente & $.0,58$ & 2 \\
\hline Partido de FHC & $.0,35$ & 2,31 \\
\hline País do MERCOSUL & $.0,24$ & 3,04 \\
\hline Presidente da Câmara & 0,02 & 1,66 \\
\hline Prefeito & 0,22 & 2,06 \\
\hline Senador & 0,3 & 2,08 \\
\hline \multicolumn{2}{|c|}{ Fonte: Elaboração do autor a partir dos dados de Baker et al (2006). } \\
\hline
\end{tabular}

\section{Exposição à informação política na imprensa}

Fraseados:

v7a_mediatvyesorno. Agora vamos fazer algumas perguntas sobre seus hábitos de assistir televisão. Você assiste a algum jornal de televisão? Sim ou não?

v7b1_mediatv1choice - v7b2_mediatv2choice. Quais são os jornais de televisão que você mais assiste? Só preciso saber de até dois que você mais assista.

1. Jornal Nacional; 2. Jornal do Almoço/RBS; 3. Jornal da Band; 4. Jornal Hoje; 5. Jornal da Record Casoy; 6. Cidade Alerta; 7. Primo Piatto-UCSTV; 8. Jornal Alterosa; 9. Bom Dia Brasil; 11. SBT Noticias; 12. Globo News; 13. Jornal da Globo; 14. Fantástico; 15. MG/TV; 16. Outros; 18. NS; 19. NR

v7b1fq_mediatv1choicefreq - v7b2fq_mediatv2choicefreq. Quantas vezes na semana você assiste a esses programas?

v8a_mediamagsyesorno. Você lê alguma revista que fale sobre assuntos políticos? Sim ou não? v8b1_mediamags1choice - v8b2_mediamags2choice Quais são as que você mais lê? Só preciso saber de até duas revistas que você leia?

1. Veja; 2. Isto é; 3. Época; 4. Caros Amigos; 5. Carta Capital; 6. Exame; 7. Outra; 8. NS; 9. NR

v8b1fq_mediamags1choicefreq -v8b2fq_mediamags2choicefreq. Quantas vezes por mês você lê cada uma?

v9a_mediapaperyesorno. Você lê notícias sobre política e economia em jornais? Sim ou não? v9b1_mediapaper1choice - v9b2_mediapaper2choice. Quais são os que você mais lê?

1. Zero Hora; 2. Pioneiro; 3. Correio do Povo; 4. O Sul; 5. Correio Riograndense; 6. Jornal do Comércio; 7. Tribuna de Minas; 8. Estado de Minas; 9. Diário Regional; 10. O Globo; 11. Extra; 12. Jornal do Brasil; 13. O Dia; 14. Folha de São Paulo; 15. Estado de São Paulo; 16. Gazeta Mercantil; 17. Outros ; 18. NS; 19. NR

v9b1fq_mediapaper1choicefreq - v9b2fq_mediapaper2choicefreq. Quantas vezes por semana você lê esses jornais?

A Análise Fatorial da matriz de correlações policóricas entre os itens de exposição à informação política na imprensa revelou a existência de duas dimensões latentes. Os itens de exposição à TV carregaram em uma dimensão, enquanto os itens de exposição a revistas e a jornais carregaram em outra. Nessa análise, foi preciso utilizar a rotação oblíqua dos fatores, a qual permite que eles se 
BATISTA PEREIRA, F. Sofisticação política e opinião pública no Brasil: revisitando...

correlacionem. Foi utilizado o somatório dos itens para se manter a interpretação direta da variável em termos do número absoluto de vezes que o respondente declarou ter assistido TV, lido jornais e revistas.

\section{Exposição à informação política em conversas}

Fraseados:

v16a_conversegroups. Com qual frequência você conversa sobre política nos grupos em que participa? Frequentemente, Às vezes, Raramente ou Nunca?

v16b_conversenotamob. Com que frequência você conversa sobre política com pessoas do seu bairro que não sejam da Associação de Moradores do Bairro?

v16c_converseworksorschool. Com que frequência você conversa sobre política no trabalho ou na escola?

v16d_conversecommute. E no trajeto para o trabalho?

v16e_conversefriends. Com que frequência você conversa sobre política com amigos?

v16f_converseshopping. Quando você está fazendo compras?

v16g_conversefamily. Com que frequência você conversa sobre política com membros da sua família?

A Análise Fatorial da matriz de correlações policóricas permitiu constatar que os itens de exposição à informação política em conversas representam uma única dimensão latente. Sendo assim, o último passo da construção do índice de exposição à informação política em conversas foi o de submeter os itens às análises por TRI e salvar o escore. Como os itens não são binários, utilizou-se o Modelo de Reposta Gradual (MRG), que é um modelo de TRI adaptado para itens ordinais (RIzoPouLOS, 2006, p. 3). O construto final foi re-escalado de modo a variar entre 0 (Nunca) e 3 (Quase toda semana), a mesma escala da pergunta original.

\section{Associativismo}

Fraseados:

v14a_groupsamob. Agora eu vou ler uma lista de grupos e associações. Eu gostaria que você me dissesse qual é a frequência com que participa de reuniões desses grupos. Com qual frequência você participa de reuniões da Associação de Moradores: nunca, algumas vezes por ano, uma ou duas vezes por mês ou quase toda semana?

v14d_groupsunion. Sindicato

v14e_groupsparty. Partido Político

A Análise Fatorial da matriz de correlações policóricas indicou que é possível utilizar os três itens como representantes do grau de associativismo do respondente. Também foi utilizado o Modelo de Resposta Gradual para gerar o construto final, que foi re-escalado para variar entre 0 (Nunca) e 3 (Quase toda semana).

Frederico Batista Pereira - frederico.b.pereira@vanderbilt.edu

Submetido à publicação em novembro de 2011.

Versão final aprovada em maio de 2012 